\title{
REGULACIÓN DE CONFLICTOS DE INTERÉS Y DEBERES FIDUCIARIOS DE LOS DIRECTORES EN LAS UNIVERSIDADES CHILENAS*
}

\author{
Ignacio Valenzuela Nieto \\ Abogado
}

\begin{abstract}
Resumen: Este artículo analiza la lógica que puede justificar una prohibición a los fines de lucro en las universidades chilenas y los efectos que ha tenido esa prohibición en el sistema de educación superior durante las últimas décadas. Con eso en cuenta, se argumenta que las transacciones entre las universidades y sus entidades relacionadas pueden ser eficientes y se proponen luego principios para abordarlas, inspirados en la regulación de las sociedades anónimas y la experiencia internacional. Finalmente, dichos principios se complementan con propuestas para una regulación de los deberes fiduciarios de quienes sirven en directorios universitarios, apuntando a promover
\end{abstract}

Ignacio Valenzuela Nieto. Abogado de la Pontificia Universidad Católica de Chile. LLM, Columbia University. Abogado asociado en Carey. Email: imv2114@ columbia.edu.

* Este artículo se encuentra basado en un trabajo del mismo autor, de mayor extensión, titulado "La prohibición a los fines de lucro y propuestas de gobierno para las universidades chilenas", serie Propuestas de Política Pública 9, Centro de Estudios Públicos (mayo de 2015), http://www.cepchile.cl/1_5930/doc/la_prohibicion_a_ los_fines_de_lucro_y_propuestas_de_gobierno_para_las_universid.html\#.VWiaTc9Vikp/. El autor agradece los valiosos comentarios de Harald Beyer, Claudia Allende, Peter Swords y árbitros anónimos. Sin embargo, asume que los errores que pueda contener el artículo son de su exclusiva responsabilidad. 
una mayor transparencia en el funcionamiento de las universidades e incentivar la participación de personas talentosas y experimentadas en su administración.

Palabras Clave: universidad, organización sin fines de lucro, educación superior, gobierno corporativo, deberes fiduciarios, transacciones con entidades relacionadas.

RECIBIDO: marzo 2015; ACEPTADO: mayo 2015.

\title{
REGULATION OF CONFLICTS OF INTEREST AND FIDUCIARY DUTIES OF DIRECTORS IN CHILEAN UNIVERSITIES
}

\begin{abstract}
This article analyzes the logic that might justify a nondistribution constraint imposed over Chilean universities and the effects that such constraint has had in the higher education system during the last decades. Considering that particular condition, it is argued that transactions between universities and their related parties might be efficient and principles for dealing with them are then proposed, being inspired in the Chilean corporations law and the international experience. Finally, those principles are complemented with proposals for the regulation of fiduciary duties of individuals serving in universities' boards of directors, aiming to promote further transparency in the activities of universities and encourage persons with talent and experience to participate in universities' decision-making bodies.
\end{abstract}

KEYwORDs: university, non-profit organization, higher education, corporate governance, fiduciary duties, related party transactions.

RECEIVED: March 2015; ACCEPTED: May 2015.

\section{INTRODUCCIÓN: MARCO LEGAL EXISTENTE Y CONTEXTO ACTUAL}

D esde 1981, la ley obliga a las universidades chilenas a constituirse como instituciones sin fines de lucro. El artículo 15 del Decreto con Fuerza de Ley N. ${ }^{\circ} 1$ de Educación, publicado en enero de 1981, establecía que "podrán crearse universidades, las que deberán constituirse como personas jurídicas de derecho privado sin fines de lucro". ${ }^{1}$ Esta condición fue replicada en la Ley Orgánica Constitucional de Enseñan-

${ }^{1}$ Decreto con Fuerza de Ley N. ${ }^{\circ} 1$ del Ministerio de Educación Pública del 3 de enero de 1981, "Fija normas sobre universidades", República de Chile. 
za (LOCE), publicada en marzo de $1990,{ }^{2}$ y es el principio que impera en la actualidad.

La prohibición a los fines de lucro impuesta sobre las universidades chilenas ha sido determinante en la forma en que se han desarrollado estas instituciones durante las últimas tres décadas. El marco regulatorio, que además otorgó exclusividad a las universidades para el otorgamiento de ciertos títulos, no sólo condicionó el carácter de las instituciones, sino que también la forma en que éstas buscaron los recursos que necesitaban para satisfacer una creciente demanda por los programas que ofrecían. Fue así como algunas universidades recurrieron al apoyo otorgado por sociedades con las que estaban relacionadas. Dicho método, en efecto, ha contribuido de buena manera a aumentar la cobertura de la educación superior en Chile durante las últimas décadas. Sin embargo, las transacciones con entidades relacionadas no fueron reguladas por el legislador, pudiendo, por lo tanto, prestarse para la existencia de abusos que atentan contra el mejor destino de los recursos para los respectivos proyectos universitarios. Asimismo, tampoco se establecieron reglas sobre el funcionamiento de los directorios de estas instituciones ni sobre los deberes de quienes sirvieran en ellos. Estos vacíos en nuestra legislación continúan en la actualidad, y no es prudente pensar que ellos carecen de influencia en la calidad y cobertura de la educación que Chile entrega a sus estudiantes universitarios.

Chile enfrenta un momento en que el destino de su educación superior ha sido puesto en el centro del debate público. En ese contexto, este artículo aporta algunas reflexiones sobre la prohibición a los fines de lucro en las universidades chilenas y propone formas eficientes de aplicarla, de una manera que contribuya al desarrollo de tales instituciones y promueva una mejor calidad de la educación que éstas entregan a sus estudiantes.

\section{EL DESARROLLO DE LA EDUCACIÓN SUPERIOR EN CHILE EN EL PERÍODO 1981-2014}

Un breve recuento del desarrollo del sistema de educación superior en Chile a partir de 1981, año de publicación del Decreto con Fuerza de Ley N. ${ }^{\circ} 1$ de Educación, constituye una valiosa guía para comprender

${ }^{2}$ Ver Ley 18.962 del 10 de marzo de 1990, "Ley orgánica constitucional de enseñanza", República de Chile. 
las posibles motivaciones de la regulación que rige a las universidades y sus efectos.

Antes de 1981, existían ocho universidades en Chile, de las cuales dos eran estatales y seis eran privadas. La educación superior era concebida como una responsabilidad pública, asumida por el Estado en cuanto a su financiamiento y por las mismas instituciones de educación superior en su regulación. Debido a la existencia de un financiamiento público garantizado en un contexto de autorregulación, el ordenamiento ha sido denominado de "autonomía privilegiada". ${ }^{3}$ Con la normativa de 1981 se autorizó la creación de universidades privadas y, en cuerpos legales paralelos, se regularon nuevas instituciones de educación superior no universitarias. Estos eran los institutos profesionales y los centros de formación técnica, los que estaban impedidos de otorgar títulos reservados a las universidades. A diferencia de estas últimas, los institutos profesionales y centros de formación técnica no fueron sometidos al requisito de constituirse como personas jurídicas sin fines de lucro.

El 10 de marzo de 1990, un día antes de que el gobierno militar entregara el mando de la nación al Presidente Patricio Aylwin, se promulgó la LOCE. Esta ley introdujo un nuevo sistema de supervisión de las universidades privadas, basado en la acreditación entregada por un Consejo Superior de Educación. ${ }^{4}$ De acuerdo con el artículo 29 de la LOCE, el Estado reconocería oficialmente como instituciones de educación superior a las universidades, los institutos profesionales, los centros de formación técnica y otros centros de enseñanza especializada vinculados a la defensa nacional y el orden público, dependientes de instituciones del Estado, como las fuerzas armadas y Carabineros de Chile.

En dos aspectos relevantes la LOCE replicaba lo que establecía la norma de 1981. En primer lugar, el artículo 30 de dicha ley establecía que las universidades chilenas debían constituirse como corporaciones de derecho privado, sin fines de lucro. Ese artículo también hacía referencia a los institutos profesionales y centros de formación técnica, los que, tal como ocurrió en 1981, quedaron libres del requisito impuesto a las universidades. En ese esquema, si se deja afuera la enseñanza universitaria, la labor central de formación de los futuros profesionales queda-

${ }^{3}$ Ver Andrés Bernasconi y Fernando Rojas, Informe sobre la educación superior en Chile: 1980-2003 (Santiago: Editorial Universitaria, 2004), 29.

4 Ibídem, 34. 
ba entregada a los institutos profesionales, mientras que la formación de los futuros técnicos correspondería a los centros de formación técnica.

En segundo lugar, la LOCE siguió el patrón de la norma precedente al establecer que el otorgamiento del título profesional de determinadas profesiones se reservaría para las universidades (específicamente, aquellos títulos que, de acuerdo con el artículo 52 de la LOCE, requieren que la persona haya obtenido previamente el grado académico de licenciado) ${ }^{5}$

En 1990, y a pesar del ingreso de nuevos actores privados a partir de 1981, la cobertura de las universidades existentes era baja. Para entonces, la matrícula de educación superior en pregrado era de aproximadamente 245.600 estudiantes (de los cuales aproximadamente el 52 por ciento se encontraba matriculado en universidades) ${ }^{6}$ con una población entre 18 y 24 años de edad de aproximadamente 1.737 .000 jóvenes. $^{7}$ Estos datos dan cuenta de una tasa de cobertura bruta ${ }^{8}$ aproximada de 14 por ciento. En 1990, alrededor del 85 por ciento de los estudiantes que cursaban sus estudios de pregrado en universidades estaban inscritos en universidades que formaban parte del Consejo de Rectores de Universidades Chilenas (CRUCh). ${ }^{9,}, 10$

5 Ver Decreto con Fuerza de Ley N. ${ }^{\circ} 2$ del Ministerio de Educación del 2 de julio de 2010, "Fija texto refundido, coordinado y sistematizado de la Ley N. ${ }^{\circ}$ 20.370 con las normas no derogadas del Decreto con Fuerza de Ley N. ${ }^{\circ}$ 1, de 2005”, República de Chile. Esta ley describe los títulos que en la actualidad se reservan a las universidades.

${ }^{6}$ Servicio de Información de Educación Superior de Chile, "Evolución de la matrícula de pregrado por tipo de institución 1983-2013", http://www.mifuturo.cl/ index.php/estudios/estructura-compendio/.

${ }^{7}$ Instituto Nacional de Estadísticas de Chile, "Chile proyecciones y estimaciones de población. Total país 1950-2050”, http:/www.ine.cl/canales/chile_estadistico/demografia_y_vitales/proyecciones/Informes/MicrosoftWordInforP_T.pdf/.

${ }^{8} \mathrm{La}$ tasa de cobertura bruta se define para estos efectos como el total de personas en la educación superior como porcentaje del total de personas entre 18 y 24 años de edad.

${ }^{9}$ El CRUCh es una entidad creada en 1954 que en la actualidad reúne a todas las universidades estatales y no estatales existentes antes de 1981 y aquellas que con posterioridad se formaron a partir de ellas. En abril de 2015, veinticinco universidades eran miembros del CRUCh. La referencia en este artículo a universidades privadas debe entenderse hecha, en general, a las universidades no pertenecientes al CRUCh.

${ }^{10}$ Servicio de Información de Educación Superior, "Evolución de la matrícula". 
Tras el fin del régimen militar en 1990, los gobiernos democráticos que lo sucedieron se encontraron con un bajo gasto público en educación y necesidades relevantes en la educación escolar. La baja cobertura de la educación secundaria fue motivo de especial preocupación. En consecuencia, los gobiernos democráticos posteriores a 1990 reasignaron los fondos públicos destinados a educación, lo que produjo una caída considerable del gasto público relativo en educación superior.

Sin embargo, desde comienzos de los años noventa, en parte debido a los buenos resultados de la economía chilena, se produjo una creciente demanda por programas de educación superior.

Los siguientes gráficos muestran el incremento de la cobertura bruta correspondiente a pregrado y la caída del gasto público directo ${ }^{11}$ en educación superior en Chile, como porcentaje de su PIB, durante el período 1990-2012.

\section{Gráfico 1. COBERTURA BRUTA EN EDUCACIÓN SUPERIOR EN CHILE PARA EL PERÍODO 1990-2012 (SÓLO CONSIDERA PREGRADO)}

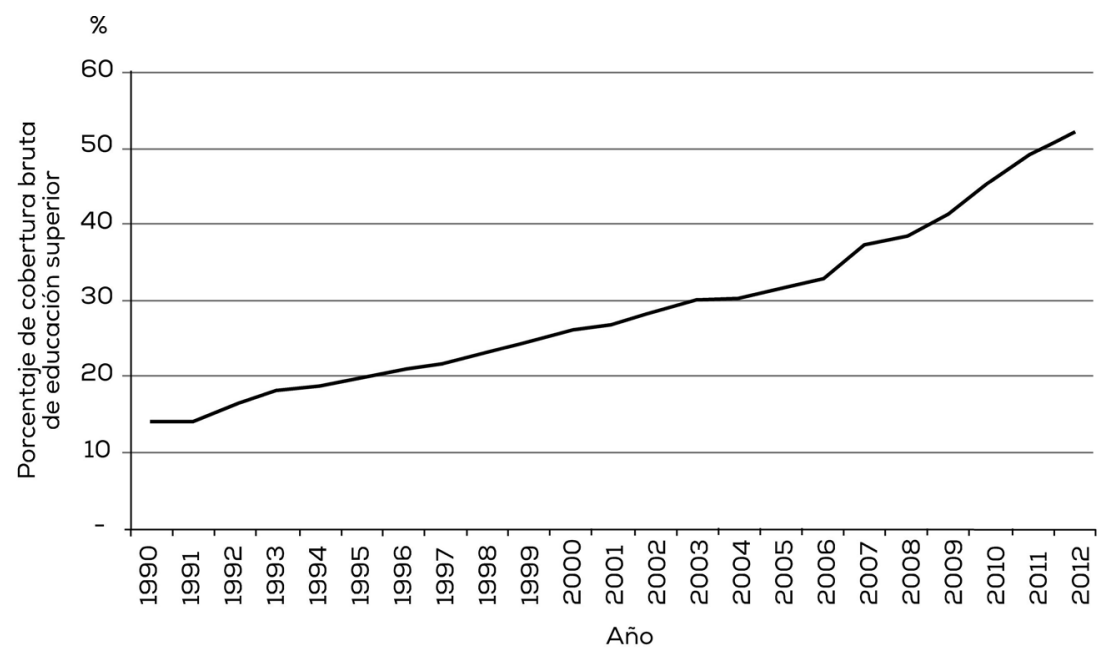

Fuente: Elaboración del autor en base a datos del Servicio de Información de Educación Superior y el Instituto Nacional de Estadisticas.

${ }^{11}$ El gasto público directo, en general, se destina a universidades del CRUCh, en base a criterios históricos. En la actualidad, la mayor parte de los aportes estatales que reciben las universidades privadas es por vía indirecta, en base al puntaje obtenido por sus estudiantes en la Prueba de Selección Universitaria. 
Gráfico 2. GASTO PÚBLICO DIRECTO EN EDUCACIÓN SUPERIOR EN CHILE, COMO PORCENTAJE DEL PIB, PARA EL PERÍODO 1990-2012

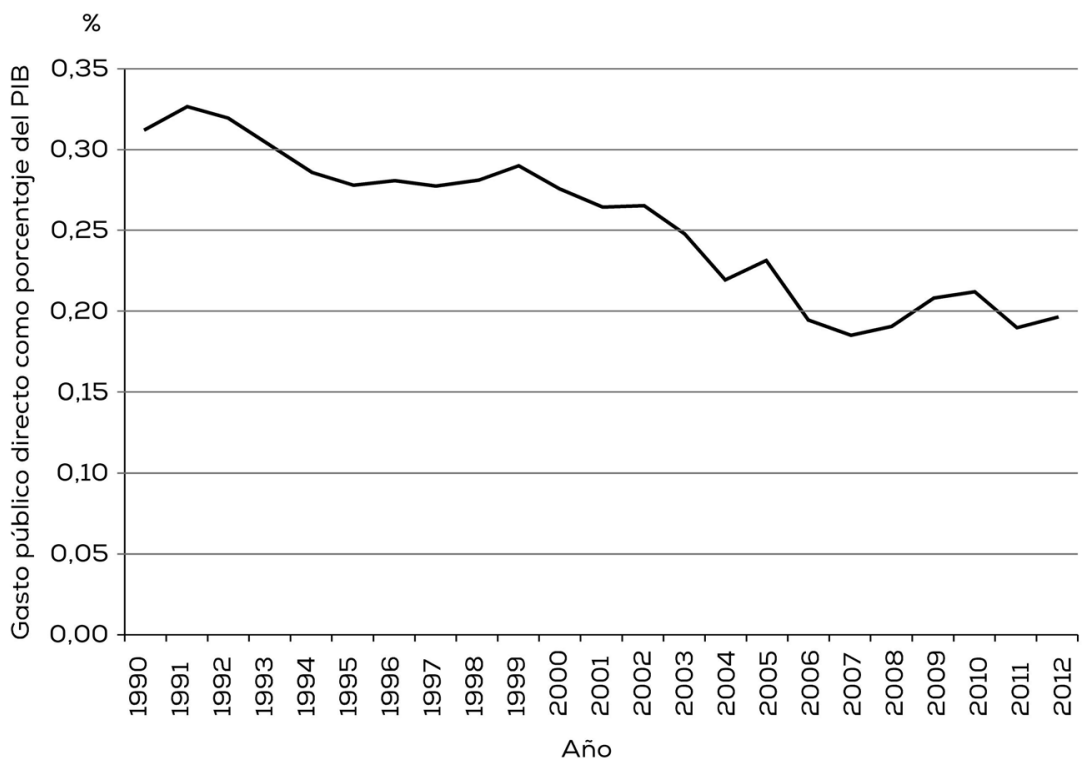

Fuente: Dirección de Presupuesto del Gobierno de Chile.

La disminución a lo largo de los años del gasto público directo relativo en educación superior y una cobertura creciente sugieren que la iniciativa privada ha sido uno de los pilares que ha permitido el crecimiento de esta cobertura.

El siguiente gráfico muestra el incremento comparado de la matrícula de pregrado de las universidades pertenecientes al CRUCh y de las universidades privadas a partir de 1984.

Las universidades privadas han crecido de manera exponencial durante los últimos 25 años y su rol sigue siendo extremadamente relevante para la educación de estudiantes provenientes de familias de diversos niveles socioeconómicos. Según datos del Ministerio de Educación, en 2014 existían 60 universidades en el país, de las cuales 35 eran privadas. ${ }^{12}$ El número total de estudiantes de educación superior en pregrado para el mismo año ascendía a 1.144.605 (de los cuales el 56 por ciento

${ }^{12}$ Ministerio de Educación de Chile, "Becas y créditos 2015", http://www.mineduc.cl/usuarios/becasycreditos/doc/201411181621000.insertoBYC_2015VF.pdf/. 
Gráfico 3. EVOLUCIÓN DE LA MATRÍCULA DE PREGRADO EN LAS UNIVERSIDADES QUE FORMAN PARTE DEL CRUCH Y EN LAS UNIVERSIDADES PRIVADAS PARA EL PERÍODO 1984-2013

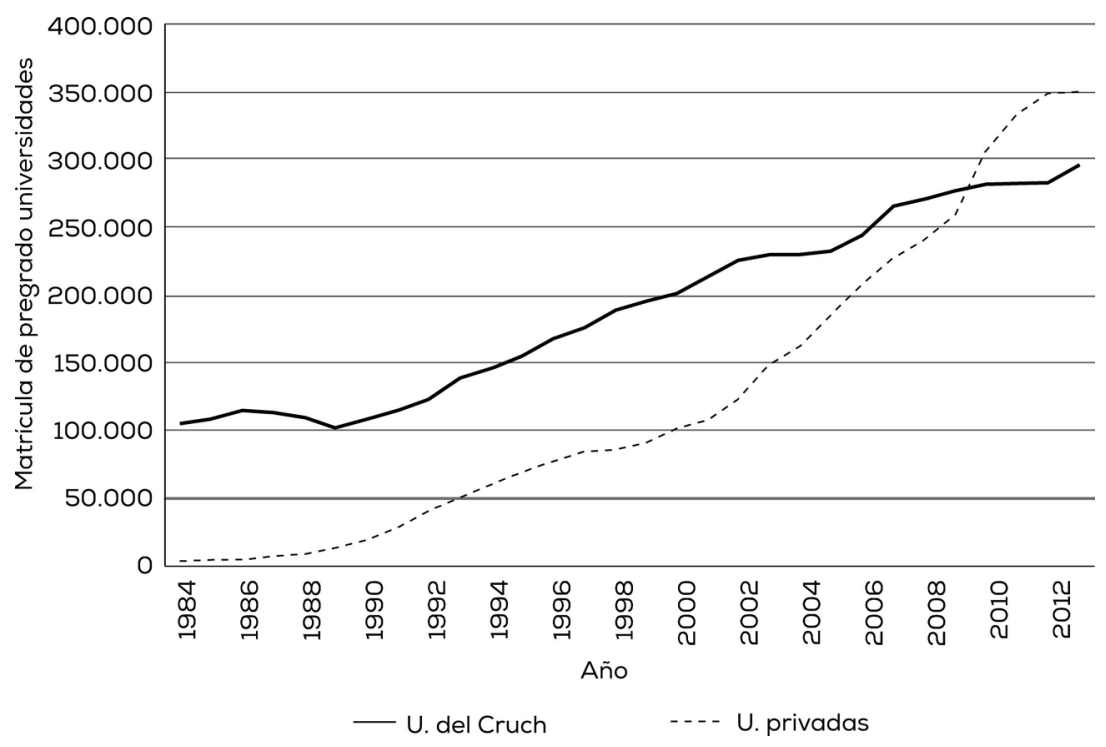

Fuente: Servicio de Información de Educación Superior.

correspondían a universidades), ${ }^{13}$ respecto de una población de entre 18 y 24 años de edad de aproximadamente 2.043 .000 jóvenes. ${ }^{14}$ Estos datos dan cuenta de una tasa de cobertura bruta cercana al 56 por ciento. En 2014, aproximadamente el 47 por ciento de los estudiantes universitarios de pregrado se encontraba matriculado en universidades del CRUCh, y el 53 por ciento restante, en universidades privadas. ${ }^{15}$ Estas cifras son un valioso antecedente para comprender los profundos cambios que ha experimentado la educación superior en Chile en los últimos veinticinco años. En este contexto de transformaciones significativas no resulta sorprendente que hayan surgido problemas y nuevos desafíos.

${ }^{13}$ Servicio de Información de Educación Superior de Chile, "Informe matrícula 2014", 17 de septiembre de 2014, http://www.mifuturo.cl/index.php/informessies/matriculados/.

${ }^{14}$ Instituto Nacional de Estadísticas, "Chile proyecciones y estimaciones".

${ }^{15}$ Servicio de Información de Educación Superior, "Informe matrícula 2014”. 


\section{LA LÓGICA DE LA PROHIBICIÓN DE LOS FINES DE LUCRO}

La prohibición de los fines de lucro no implica que las instituciones afectadas tengan prohibida la generación de utilidades. En efecto, éstas necesitan dichos excedentes para realizar las actividades propias de su giro. ${ }^{16}$ Lo que la legislación chilena prohíbe a las personas jurídicas sin fines de lucro es la distribución de utilidades. Particularmente, lo que se prohíbe en el contexto de las universidades es la distribución o el retiro de excedentes obtenidos de las actividades universitarias y cuyo destino sean los controladores y miembros de las universidades, ${ }^{17,18} \mathrm{u}$ otras personas con cargos directivos o administrativos (que no sean remuneración por sus servicios o reembolso de gastos).

No existe claridad sobre las razones que explican la opción de los legisladores chilenos por proscribir los fines de lucro en las universidades. Lo anterior se debe a la ausencia de documentos oficiales que den testimonio de los razonamientos que precedieron a los respectivos cuerpos legales de 1981 y 1990. En consideración a la distinción hecha con los institutos profesionales y centros de formación técnica (los que, como se ha señalado, no quedaron sujetos a esta prohibición), es posible que, quizás entre otras razones, se haya considerado el otorgamiento de incentivos para que las universidades emprendan en actividades de investigación, y no sólo en docentes.

${ }^{16} \mathrm{La}$ posibilidad de que las personas jurídicas sin fines de lucro obtengan utilidades está contemplada en el Código Civil. Ver Código Civil de Chile, artículo $557-2$

17 Ver Carlos Williamson, "Universidad y lucro", Estudios Públicos 128 (2012): 149-150.

18 Para efectos de este artículo, el término "controlador" o "controladores" debe entenderse haciendo referencia a las personas o entidades que dispongan, de manera última, de los destinos de una universidad, o que ejerzan una influencia relevante en la institución. Lo anterior incluye - pero no está limitado a los mismos - a quienes han realizado aportes significativos por vía de capital o deuda en la institución y quienes designen, por vía directa o indirecta, a uno o más integrantes del directorio u órgano de administración superior de la institución. "Miembros" de las universidades, por su parte, debe entenderse para estos efectos de manera amplia, incluyendo tanto a los miembros de las corporaciones universitarias como a los fundadores u organizadores de las universidades constituidas como una fundación, cualquiera sea su denominación. 
La idea de que es improbable que instituciones con fines de lucro se aboquen a actividades de investigación ha sido discutida en Chile. Según Beyer,

es importante reconocer que en el nivel terciario es casi imposible que una institución con fines de lucro sea una universidad compleja; es decir, una donde existe investigación de alto nivel y se desempeña un número elevado de docentes que no sólo hacen clases sino que investigan en asuntos de su especialidad. Las únicas instituciones de estas características son estatales o privadas sin fines de lucro. Esta realidad obedece básicamente a que crear una universidad compleja requiere de muchos recursos que sólo son posibles de obtener del erario público o de donaciones privadas. Precisamente es ese costo el que explica por qué sólo una pequeña proporción de las instituciones de educación superior en las más diversas latitudes realiza investigación avanzada. ${ }^{19}$

Estas ideas encuentran asidero en la evidencia de países con un desarrollado sistema universitario. The Carnegie Classification of Institutions of Higher Education revela que en Estados Unidos, en 2010, sólo el 6,3 por ciento de las instituciones de educación superior, que representan cerca del 28 por ciento de la matrícula total del sistema, son caracterizadas como universidades de investigación. De las consideradas como instituciones con muy alta actividad de investigación, 68 por ciento eran públicas y 32 por ciento eran privadas sin fines de lucro; mientras que de aquéllas consideradas con alta actividad de investigación, 75 por ciento eran públicas y 25 por ciento eran privadas sin fines de lucro. En estas categorías no había una sola universidad privada con fines de lucro. ${ }^{20}$ Estos antecedentes sugieren que en sistemas universitarios masivos sólo un pequeño porcentaje de las universidades son instituciones complejas con niveles avanzados de investigación y programas de doctorado. En Estados Unidos al menos, dichas universidades reciben una parte importante de su financiamiento de donaciones, así como fondos gubernamentales para financiar sus actividades de investigación.

19 Harald Beyer, "La discusión sobre el lucro: ¿acento correcto?", Revista Capital, 18 de octubre de 2011, http://www.brunner.cl/?p=2235 (accedida el 11 de abril de 2015).

20 The Carnegie Classification of Institutions of Higher Education, http://carnegieclassifications.iu.edu/summary/basic.php (accedida el 5 de abril de 2015). 
En Latinoamérica, el panorama de la diversidad de la educación superior no es distinto. Sobre un total de aproximadamente 3.530 universidades, cerca de 50 pueden ser caracterizadas como universidades "de investigación" o "con investigación", y otras 130 como universidades "emergentes en la investigación". ${ }^{21}$ Así las cosas, en conjunto, sólo cerca del 5,1 por ciento del total de las universidades de la región posee alguna producción relativamente continua de trabajos de investigación.

Considerando estos antecedentes, a lo que se suma la falta de una tradición filantrópica que favorezca a las universidades chilenas y la relativamente limitada disponibilidad de fondos públicos para investigación en las universidades privadas, ${ }^{22}$ es posible comprender que la idea de que una generalidad de las universidades se aboque a tareas de investigación es difícil de ser llevada a la práctica. Más aún, la exclusividad que recibieron las universidades chilenas para otorgar determinados títulos derivó en que, en cierta medida, ellas tuvieran incentivos para abandonar aspiraciones investigadoras en pos de destinar mayores recursos a actividades de docencia. En efecto, según la misma caracterización referida para las universidades latinoamericanas, en Chile, de un total de 60 universidades existentes, sólo 3 son caracterizadas como universidades "de investigación" o "con investigación", y otras 13 como universidades "emergentes en la investigación". 23

Adicionalmente, la experiencia en países desarrollados muestra que las universidades que desarrollan muchas actividades de investigación tienen menos estudiantes que sus pares que no han tomado esa opción (o, al menos, no con la misma intensidad) y, ciertamente, mu-

${ }^{21}$ Ver José Joaquín Brunner y Cristóbal Villalobos, Políticas de educación superior en Iberoamérica, 2009-2013 (Santiago: Ediciones Universidad Diego Portales, 2014), 27-29. Los datos aquí presentados han sido adaptados a partir de los indicados en aquel trabajo. La caracterización se ha realizado en base al número total de documentos publicados por cada universidad en revistas académicas indizadas en Scopus entre los años 2008 y 2012.

${ }^{22}$ En 2014, el 93,9 por ciento de los fondos de investigación Conicyt fueron entregados a universidades del CRUCh (estatales y no estatales). Ver Contraloría General de la República de Chile, "Financiamiento fiscal a la educación superior 2014", http://www.contraloria.cl/NewPortal2/portal2/ShowProperty/BEA\%20 Repository/Portal/Bases/Contabilidad/Universidades_del_Estado/Estudios/2014/ FFES.pdf/.

${ }^{23}$ Brunner y Villalobos, Políticas de educación superior, 27. 
chos menos estudiantes que las universidades chilenas, especialmente en pregrado. ${ }^{24}$

Haya sido o no el fomento de la investigación una de las motivaciones que originalmente tuvieron los legisladores para imponer una prohibición a la distribución o retiro de excedentes impuesta sobre las universidades y sus miembros, hay otros buenos argumentos que en la actualidad justifican esa alternativa. Entre ellos se cuentan (i) las asimetrías de información que se generan entre las universidades y sus estudiantes, a causa de que los estudiantes carecen de las herramientas para comprender las consecuencias particulares que para ellos tiene seguir un programa de estudios; (ii) la remoción de incentivos para que las universidades capten alumnos en exceso de aquellos a los que pueden entregar educación de buena calidad; (iii) el alto costo de cambiar de programas de estudio y la larga duración de las carreras, ${ }^{25}$ lo que posiblemente lleve a los estudiantes a preferir universidades que estén obligadas a reinvertir sus utilidades por sobre aquellas enfocadas en obtener un mayor beneficio privado para sus dueños; y (iv) la experiencia de países donde se permite la educación universitaria con fines de lucro

24 Por ejemplo, en 2014, la matrícula de la Universidad de Columbia era de aproximadamente 8.600 alumnos en programas de pregrado y 18.900 en programas de postgrado y escuelas profesionales; en Harvard, era de aproximadamente 6.700 alumnos en programas de pregrado y 14.500 en programas de postgrado y escuelas profesionales; y en Yale, era de aproximadamente 5.400 alumnos en programas de pregrado y 6.500 en programas de postgrado y escuelas profesionales. Todas estas universidades son privadas y sin fines de lucro y, de acuerdo con The Carnegie Classification of Institutions of Higher Education, todas son caracterizadas como universidades de investigación del más alto nivel. Estas cifras contrastan con los aproximadamente 30.900 estudiantes de pregrado y 8.000 estudiantes de postgrado matriculados en la Universidad de Chile (2013), los aproximadamente 22.700 estudiantes de pregrado y 4.700 estudiantes de postgrado matriculados en la Pontificia Universidad Católica de Chile (2014), y los aproximadamente 34.500 alumnos de pregrado y 4.100 estudiantes de postgrado matriculados en la Universidad Nacional Andrés Bello (2013) (todos los datos sobre matrícula han sido obtenidos de los sitios web de las respectivas universidades, el 15 de febrero de 2015).

${ }^{25}$ Según datos para el año 2012, las carreras en Chile duran en promedio 6,3 años, mientras que la duración promedio de las carreras para los países miembros de la OECD es de 4,3 años. Ver presentación "Estados financieros 2012 de las instituciones de educación superior”, http:/www.mifuturo.cl/index.php/2013-03-0618-20-53/noticias/312-mineduc-entrega-informacion-financiera-de-las-instituciones (accedida el 10 de abril de 2015). 
(como Estados Unidos y Brasil), que algunos califican como desalentadora. ${ }^{26}$

Con lo anterior no se quiere negar la posibilidad de que prestadores con fines de lucro, en la medida en que estén sujetos a un minucioso monitoreo estatal de sus actividades, examen de los resultados de la educación que entregan (campo en el que Brasil y Colombia están haciendo considerables esfuerzos, evaluando a los estudiantes antes y después de sus programas de estudio $)^{27}$ y amplia difusión de información pertinente, puedan contribuir al sistema universitario con programas que se adapten a las necesidades de la población. Estos podrían ofrecer, por ejemplo, alternativas de estudio a quienes no les resulta posible o conveniente seguir el modelo tradicional de enseñanza universitaria, a través de programas flexibles o cursos en línea. Incluso el argumento según el cual sólo prestadores sin fines de lucro se dedicarán a actividades de investigación puede ser rebatido. Tener fines de lucro no ha sido obstáculo para que industrias como la farmacéutica, aeroespacial, de

${ }^{26}$ Un estudio afirma que, en Estados Unidos, los estudiantes de instituciones de educación superior con fines de lucro tienen un mayor desempleo y menores ingresos por empleos que sus pares que asistieron a instituciones públicas o sin fines de lucro, transcurridos seis años del ingreso a sus programas de estudio. Indica, además, que los primeros muestran un considerable menor cumplimiento en el pago de sus deudas universitarias que los segundos. Ver David J. Deming et al. "The ForProfit Postsecondary School Sector: Nimble Critters or Agile Predators?”, National Bureau of Economic Research, Working Paper 17710 (2011): 3, http://www.nber. org/papers/w17710.pdf/. En ese mismo país, un reporte de un comité del Congreso, publicado en 2012, reveló que instituciones de educación superior con fines de lucro destinaron el 22 por ciento de sus ingresos para marketing, publicidad, reclutamiento y admisiones, y sólo el 18 por ciento de tales ingresos para la enseñanza de sus alumnos. Ver "Special Report: Universities", The Economist, 28 de marzo de 2015. En Estados Unidos han sido también frecuentes acciones de protección al consumidor por fraudes y abusos por parte de operadores de establecimientos de educación superior con fines de lucro, entre otras acciones e investigaciones relativas a dichos operadores iniciadas por autoridades gubernamentales. Ver Kevin Kinser, "The Rise and Fall of For-Profit Higher Education", The Nelson A. Rockefeller Institute of Government (2011), http://www.rockinst.org/observations/kinserk/201108-for-profit_higher-ed.aspx. Respecto de Brasil, en tanto, se ha afirmado que el aumento de la regulación estatal en la educación superior, motivada por el ingreso de prestadores con fines de lucro, ha producido una intervención altamente centralizada y politizada. Ver Claudio Rama, "La educación superior privada en Brasil", Revista Histedbr On-Line 11, n. ${ }^{\circ} 44$ (2011): 6, https://www.fe.unicamp.br/revistas/ ged/histedbr/article/view/3118/2773/.

${ }^{27}$ Ver The Economist, "Special Report". 
tecnología o salud realicen investigación al más alto nivel (aunque esas industrias, a diferencia de las universidades, dependen casi enteramente de su capacidad de innovar). Para que ello ocurra, sin embargo, es muy probable que el Estado tenga que financiar de manera importante las iniciativas de investigación de las universidades privadas.

Las universidades con fines de lucro son un fenómeno relativamente reciente, por lo que se carece todavía de la experiencia suficiente para extrapolar su evolución futura. En cualquier caso, existen buenas razones que respaldan la idea de que las instituciones de educación superior sin fines de lucro no sólo deberían permitirse, sino también promoverse. El interés público envuelto en la educación de los ciudadanos y las razones previamente señaladas son argumentos sólidos para permitir, mantener y legislar sobre el funcionamiento de universidades sin fines de lucro. ${ }^{28}$

Asumiendo entonces que las instituciones sin fines de lucro son deseables en la educación superior (aunque no sea de manera exclusiva), se analiza a continuación cómo, considerando la situación actual en Chile, debiera aplicarse la prohibición al retiro de excedentes. El foco principal serán las transacciones que las universidades llevan a cabo con sus entidades relacionadas y propuestas sobre los estándares para regir los deberes fiduciarios de los directores de universidades.

\section{TRANSACCIONES CON ENTIDADES RELACIONADAS QUE INVOLUCRAN A UNIVERSIDADES SIN FINES DE LUCRO}

\section{A. ¿Deberían permitirse las transacciones entre las universidades y sus entidades relacionadas?}

En la actualidad no existen normas legales directamente dirigidas a hacer cumplir la prohibición de retiro de excedentes que afecta a las universidades chilenas. Sin perjuicio de lo anterior, la ley le confiere

${ }^{28}$ Para una discusión más extensa sobre razones que justifican una prohibición de los fines de lucro en las universidades, y educación superior con fines de lucro, ver Ignacio Valenzuela, "La prohibición a los fines de lucro y propuestas de gobierno para las universidades chilenas", serie Propuestas de Política Pública 9, Centro de Estudios Públicos (mayo de 2015), http://www.cepchile.cl/1_5930/doc/ la_prohibicion_a_los_fines_de_lucro_y_propuestas_de_gobierno_para_las_universid.html\#.VWiaTc9Vikp/. 
al Ministerio de Educación la autoridad para cancelar la personalidad jurídica de las universidades que, entre otras faltas, no cumplan con sus objetivos estatutarios o incurrieren en infracciones graves a sus estatutos, así como la tarea de velar por el cumplimiento de las normas legales y reglamentarias que regulan la educación superior. ${ }^{29}$ Se trata de mandatos que caben dentro de la descripción general de las labores de dicho ministerio, el que, sin embargo, no se encuentra dotado de las atribuciones y recursos que en la práctica son necesarios para fiscalizar el cumplimiento de la prohibición de retiro de excedentes (especialmente, si se considera que la violación de esta prohibición puede involucrar transacciones complejas con entidades cuya supervisión excede el ámbito de autoridad del Ministerio de Educación).

Se ha sostenido reiteradamente en las últimas décadas que algunos controladores de las universidades chilenas, recurriendo a transacciones con entidades relacionadas, obtienen injustamente utilidades que provienen de las actividades de las universidades. Las normas legales aplicables a las universidades no prohíben las transacciones entre éstas y sus entidades relacionadas. Sin embargo, en la medida en que estas transacciones impliquen condiciones inequitativas para la universidad, a través de ellas se puede transgredir el espíritu de la ley, pues por vía indirecta se vulnera la prohibición al retiro de excedentes. Lo anterior, porque las entidades relacionadas a las universidades no se encuentran afectas a esa prohibición.

El objetivo de las transacciones con entidades relacionadas es la provisión de todo tipo de bienes y servicios a cambio de una compensación. Estos bienes y servicios pueden ser provistos por las entidades relacionadas a la universidad, efectuando esta última un pago; o por la universidad a las entidades relacionadas, las que efectúan un pago a la universidad. Si bien la primera modalidad es la que genera riesgos para el retiro indebido de excedentes de las universidades; en realidad, ambas modalidades son relevantes, en cuanto, al existir un conflicto de interés, cualquiera de ellas puede perjudicar a la univer-

${ }^{29}$ Ver artículo 64 del Decreto con Fuerza de Ley N. ${ }^{\circ} 2$ del Ministerio de Educación de 2010, y artículos 2 y 8 de la Ley 18.956 del 8 de marzo de 1990, "Reestructura el Ministerio de Educación Pública”, República de Chile. 
sidad. ${ }^{30}$ Una parte importante de las transacciones que las universidades realizan con sus entidades relacionadas son operaciones entre la universidad e inmobiliarias ligadas a los controladores de la misma, las que construyen o adquieren edificios para uso de la universidad que luego son arrendados a esta última. Estas transacciones son altamente relevantes para las universidades, puesto que las instituciones requieren de dichos inmuebles para realizar sus actividades rutinarias. Las transacciones que celebran las universidades con sus entidades relacionadas (sea que involucren inmuebles, asesorías u otros bienes o servicios) no necesariamente son realizadas a valores de mercado, y de ahí que son una vía para permitir la transferencia de utilidades desde la universidad a sus controladores.

Por lo general, cuando se habla de transacciones con entidades relacionadas en el caso de las universidades, deben considerarse las operaciones entre esta institución de educación superior y cualquier persona natural o jurídica que ejerza respecto de ella una influencia relevante, sea por su condición de miembro o bien por ser integrante de sus órganos de administración. La generalidad de las veces, se tratará de transacciones con entidades que están bajo el mismo control que la universidad.

Las normas que de manera específica regulan la constitución y funcionamiento de las universidades no tratan las transacciones entre éstas y sus entidades relacionadas. Por su parte, la regulación de las personas jurídicas sin fines de lucro - contenida en el Título XXXIII del Libro I del Código Civil, cuyas reglas se aplican supletoriamente a las universidades - ${ }^{31}$ contiene sólo una norma que (de manera muy limitada) trata uno de los aspectos descritos en el párrafo anterior. Dicha regla prescribe que los directores de instituciones sin fines de lucro ejercerán

30 Según información entregada por el Ministerio de Educación el año 2012, el 90 por ciento de las universidades del país manifestaron tener vínculos con entidades relacionadas. El año 2011, las universidades del CRUCh reportaron 170 transacciones con entidades relacionadas, mientras que las universidades privadas reportaron 176 transacciones de ese tipo. Ver "E1 90\% de las instituciones de educación superior mantiene empresas relacionadas", La Tercera, 21 de agosto de 2012, http://www.latercera.com/noticia/educacion/2012/08/657-479239-9-mineduc-el90-de-las-instituciones-de-educacion-superior-mantiene-empresas.shtml (accedida el 10 de abril de 2015).

${ }^{31}$ Ver artículos 30 y 84 de la Ley 18.962 de 1990. 
su cargo gratuitamente, pero pueden ser retribuidos por otros servicios que presten a la organización. ${ }^{32}$

Puede pensarse que la omisión de una regulación sobre las transacciones con entidades relacionadas llevadas a cabo por las universidades chilenas (o una ausencia de prohibición) correspondió, en su momento, a un error de los legisladores. Sea o no de tal manera, en una época de creciente debate público sobre la educación, una definición esencial es si estas prácticas son valiosas desde un punto de vista social y si, según ello, deben o no ser permitidas.

Por un lado, hay quienes sostienen que, en atención a que las transacciones entre las universidades y sus entidades relacionadas dan lugar a repartos encubiertos de utilidades, violando si no la letra, al menos el espíritu de la ley, éstas debieran derechamente prohibirse. Se ha argumentado que los controladores de las universidades, en lugar de arrendar a estas últimas los inmuebles que utilizan, debieran escoger entre mantener el control de la universidad o quedarse con el control de la sociedad relacionada. Así — se propone - no se desalentarían los intercambios, sino que los conflictos de interés con los que estos se realizan, y existiría, además, una separación entre las instituciones de transmisión cultural (como es el caso de las universidades) de los negocios puramente mercantiles. ${ }^{33} \mathrm{Si}$ la opción es prohibir las transacciones con entidades relacionadas, otra forma de implementar la prohibición es mediante la transferencia forzosa de los activos que arriendan las universidades a estas últimas.

Por otro lado, puede argumentarse que, puesto que en Chile las donaciones no han constituido una fuente importante de recaudación de fondos para las universidades, y las universidades privadas no han recibido, por lo general, recursos públicos de manera directa, el financiamiento a través de entidades relacionadas ha sido clave para el desarrollo de los planes de inversión de tales universidades. Estos planes les han permitido expandir su oferta de carreras, en línea con la creciente demanda por parte de los estudiantes. Así, hay quienes han sostenido que detrás de la falta de regulación relativa a las transacciones entre las universidades y sus entidades relacionadas habría "un propósito claro de permitir que los distintos factores, particularmente el capital necesa-

${ }^{32}$ Ver Código Civil de Chile, artículo 551-1.

33 Ver Carlos Peña, "La universidad y el lucro: cómo impedirlo y por qué", Estudios Públicos 128 (2012): 130. 
rio para desarrollar la infraestructura, fuera remunerado". ${ }^{34}$ Se menciona que "no proveyéndola el Estado mediante su intervención directa, si no se hubiera permitido la remuneración de los distintos factores, habría sido inviable el crecimiento de infraestructura y el aumento de oferta universitaria". ${ }^{35}$ Se ha señalado también que, debido a la escasa filantropía, las fuentes de financiamiento para las universidades privadas han sido el endeudamiento (de difícil acceso para las universidades y modesto atendido el volumen de recursos que se requieren) o el apoyo de sociedades relacionadas. ${ }^{36}$ Así, "quizás por ello la legislación chilena no estableció mayores exigencias a las formas en que las universidades allegaban recursos, estableciendo sólo principios generales como que las corporaciones universitarias no podían tener fines de lucro". ${ }^{37}$

Considerando los costos y beneficios que cada posición en el debate conlleva, existen razones teóricas y prácticas para respaldar la idea de que permitir estas transacciones - con limitaciones - es la solución más eficiente. Entre ellas, cabe mencionar las siguientes:

1. El conocimiento lleva a resultados eficientes. Las entidades vinculadas al control de una universidad tienen una comprensión privilegiada de la forma en que esta última opera; esto es, de sus necesidades, potencialidades y la mejor forma de asignar sus recursos. Saben cuándo y en qué medida algo es conveniente o necesario. Más aún, las universidades pueden reducir de manera significativa sus costos de transacción cuando operan con sus entidades relacionadas. ${ }^{38}$ De esta manera lo explican Fishman y Schwarz:

¿No sería una prohibición contra cualquier conflicto de interés por parte de las instituciones sin fines de lucro demasiado se-

34 Ricardo Paredes, "Universidad y lucro o el dilema de la cobertura", Estudios Públicos 128 (2012): 182.

35 Ídem.

${ }^{36}$ Ver Harald Beyer, "Una agenda para la educación superior", Centro de Estudios Públicos, Documento de Trabajo 390 (enero 2013): 5, http://www.cepchile. cl/dms/archivo_5235_3352/HBeyer_presentacion.pdf/.

37 Ídem.

${ }^{38}$ En este sentido, Williamson sostiene que "el modelo de sociedades relacionadas puede ser virtuoso para la gestión universitaria y la promoción de desarrollos innovadores en educación, ciencia y tecnología". Ver Williamson, "Universidad y lucro", 153. 
vera, al incluir útiles transacciones con entidades relacionadas que las instituciones sin fines de lucro, especialmente las más pequeñas, necesitan para sobrevivir? Una prohibición absoluta ignora la realidad de gran parte del sector sin fines de lucro (...). Las transacciones con entidades relacionadas son eficientes. Los costos de transacción son bajos. Los directores interesados podrían prestar dinero o proveer servicios o hacer negocios con una institución sin fines de lucro a menores costos porque, mejor que cualquier otro, conocen a la organización (...). Una institución sin fines de lucro perdería frecuentemente ventajosas oportunidades, que de otra manera le estarían disponibles, si se le prohibiera completamente realizar cualquier transacción con cualesquiera de sus directores o entidades en que los directores tienen interés. ${ }^{39}$

\section{Falta de otros métodos para obtener financiamiento. A diferen-} cia de la situación en Estados Unidos, donde es común que las universidades privadas mantengan endowments provenientes de donaciones y reciban considerables aportes estatales para investigación, las universidades chilenas no obtienen mucho de la filantropía ${ }^{40}$ y los recursos públicos que reciben las universidades privadas han sido relativamente limitados. En ese escenario adverso, las entidades relacionadas a las universidades han obtenido históricamente valiosos financiamientos de bajo costo, los que han sido utilizados para cubrir las necesidades de tales universidades. Beyer sostiene que, siendo las universidades (al menos en su fase inicial) deudoras poco atractivas (por su condi-

39 James J. Fishman y Stephen Schwarz, Cases and Materials on Nonprofit Organizations (New York: Foundation Press, 1995), 221.

40 Sólo en el año académico 2012-2013, los colleges y universidades de Estados Unidos recibieron 33.800 millones de dólares en donaciones. La Universidad de Stanford por sí sola logró en ese mismo período reunir 931,6 millones (todas las cifras en dólares de Estados Unidos). Ver "Colleges Raise Record \$33.8 Billion Exceeding U.S. Peak in 2009”, Bloomberg, 12 de febrero de 2014, http:// www.bloomberg.com/news/articles/2014-02-12/college-donations-rise-to-recordas-stocks-gain-fueled-giving (accedida el 28 de febrero de 2015). En contraste, el monto anual promedio donado a universidades chilenas bajo franquicias tributarias entre los años 2007 y 2010 fue del orden de 18 mil millones de pesos (a valor del año 2010). Estos aportes, por lo demás, se concentran en un reducido grupo de instituciones. Ver Ernesto Vargas y Claudia Martínez, "Evaluación del sistema de franquicias tributarias para donaciones a universidades en Chile", Trabajos de Investigación en Politicas Públicas 12 (2012): 6-8, http://www.econ.uchile.cl/uploads/ publicacion/aa496d822815db1c812d016694dc5ee46c98e685.pdf/. 
ción de instituciones sin fines de lucro), el endeudamiento directo no ha resultado una fórmula de financiamiento relevante. En cambio, las entidades relacionadas han tenido más capacidad de conseguir financiamiento, puesto que han podido ofrecer garantías más confiables que las propias universidades (incluso con avales de personas naturales). ${ }^{41}$ Ello facilitó "la obtención de créditos o aportes de capital que permitieron, por ejemplo, desarrollar los planes de inversión necesarios para que las universidades pudieran atender a los estudiantes que se matriculaban en sus programas". ${ }^{42}$ Beyer agrega que la flexibilidad que se ha producido por falta de una regulación detallada, "mirado retrospectivamente, (...) ha sido útil, porque ha permitido satisfacer más rápido la demanda por acceso a la educación superior" 43 y que la posibilidad de obtener financiamiento a través de terceros "ha sido instrumental a la aspiración política transversal de aumentar la cobertura en educación superior". ${ }^{4}$

\section{Elevado costo de transferencia de inmuebles desde las entida-} des relacionadas a las universidades. La infraestructura utilizada por muchas universidades pertenece a entidades relacionadas que obtuvieron financiamiento para su construcción o adquisición. Una prohibición total a las transacciones entre las universidades y sus entidades relacionadas obligaría a que se realizara la transferencia forzosa de los inmuebles de propiedad de las entidades relacionadas a las universidades que los utilizan o, alternativamente, a requerir que la entidad relacionada transfiera los inmuebles a un tercero no relacionado (o, lo que es equivalente, que los controladores enajenen su participación en la entidad relacionada). Si la primera fuera la alternativa escogida, considerando las significativas inversiones realizadas por las entidades relacionadas en infraestructura y equipamiento, cabe anticipar que las transferencias serían numerosas y de montos relevantes. Naturalmente, las universidades no pueden correr el riesgo de perder las instalaciones que utilizan para sus actividades cotidianas, las que, de no mediar

${ }^{41}$ Ver Beyer, "Una agenda", 5.

42 Ídem. Además, Beyer aporta como evidencia que, según antecedentes del Consejo Nacional de Educación, entre 1997 y 2007, la infraestructura de las universidades chilenas privadas habría crecido en 311 por ciento, mientras que la de las universidades del CRUCh lo hizo sólo en 21 por ciento (ibídem, 4).

43 Ibídem, 5.

44 Ídem. 
nuevos proyectos o circunstancias extraordinarias, seguirán siendo las más propicias para desarrollar su actividad. Esta situación pondría a las entidades relacionadas propietarias de los inmuebles en una posición privilegiada a la hora de negociar con las universidades las condiciones para la transferencia. Es así posible que, finalmente, esas transacciones no se realicen a valor de mercado, riesgo que justifica que las mismas sean reguladas. Sin embargo, ello no agota el problema, pues también habría que determinar el precio de referencia que se utilizará para las transferencias (¿valor de libro?, ¿valor actual?, ¿valor esperado en el futuro?, ¿a qué plazo?). ${ }^{45}$ La alternativa de transferir las propiedades a terceros no relacionados no parece ser una mejor solución. Ello porque esta opción también pondría a la universidad en la posición incómoda de tener que negociar con terceros el arriendo de activos que son esenciales para su funcionamiento, y donde los costos de recurrir a cualquier solución alternativa (como trasladar la universidad a otro lugar) pueden ser extraordinariamente elevados. ${ }^{46,47}$

\section{B. Marco jurídico propuesto para regular las transacciones entre las universidades y sus entidades relacionadas.}

Durante el gobierno del Presidente Sebastián Piñera, el Ministerio de Educación preparó un proyecto de ley que fue enviado al Congreso, el cual proponía la creación de una Superintendencia de Educación Superior y la regulación de materias relativas al gobierno de las universidades (en adelante, el "proyecto de ley"). ${ }^{48}$ Esa propuesta adoptó un enfoque que, sin prohibir las transacciones entre las universidades y

${ }^{45}$ Ver Williamson, "Universidad y lucro", 151-152.

46 Ídem.

${ }^{47}$ Es importante considerar que en enero de 2015 el Congreso de Chile aprobó un proyecto de ley que prescribe que los colegios que reciben subvención estatal, dentro de un cierto plazo, deberán convertirse en corporaciones sin fines de lucro e incorporar a su propiedad los inmuebles que utilizan, recibirlos en comodato o, bien, arrendarlos a un tercero no relacionado o sin fines de lucro. Para una propuesta de implementación de una regla semejante en las universidades, para el caso que el Gobierno opte nuevamente por estas ideas en un futuro proyecto de ley referido a esas instituciones, ver Valenzuela, "La prohibición", 24-25.

${ }^{48}$ Ver Presidencia de la República de Chile, "Mensaje de S.E. el Presidente de la República con el que inicia un proyecto de ley que crea la Superintendencia de Educación Superior (Mensaje N. ${ }^{\circ}$ 277-359)", 10 de noviembre de 2011. 
sus entidades relacionadas, las restringía. Los fundamentos de muchas de las normas contenidas en el proyecto de ley fueron tomados del título XVI de la Ley 18.046 del 22 de octubre de 1981 (la "Ley sobre sociedades anónimas"), que impone restricciones considerables a las sociedades anónimas abiertas para realizar operaciones con sus partes relacionadas. El proyecto de ley fue retirado del Congreso durante las primeras semanas del gobierno de la Presidenta Michelle Bachelet.

Habiendo ya analizado por qué permitir y restringir las transacciones con entidades relacionadas es una mejor solución que prohibirlas, es importante establecer los principios que debieran orientar una futura reglamentación de dichos asuntos. El proyecto de ley tenía un enfoque en la dirección correcta. En atención a que, en la práctica, el Ministerio de Educación carece de las atribuciones y los recursos necesarios para fiscalizar adecuadamente a las universidades en el cumplimiento de la ley, un organismo especializado dotado de personalidad jurídica y patrimonio propio, como la Superintendencia de Educación Superior propuesta en el proyecto de ley, resulta necesario para llevar adelante labores de monitoreo de las instituciones de educación superior, incluyendo velar por el cumplimiento de la prohibición al reparto de excedentes impuesta sobre las universidades. Las propuestas mencionadas más adelante consideran la existencia de una autoridad de ese tipo. Además de crear la mencionada autoridad, y con respecto a las transacciones con entidades relacionadas, el mérito de los autores del proyecto de ley está en que, primero, identificaron que las transacciones con entidades relacionadas son un medio a través del cual las universidades pueden eludir la prohibición al reparto de excedentes impuesta por la legislación; segundo, concluyeron que, en vez de prohibir dichas transacciones, resultaba más realista y eficiente limitarlas; y, por último, hicieron esfuerzos por adaptar a la realidad de las universidades las normas que, desde hace algunos años, rigen las transacciones con entidades relacionadas en entidades sofisticadas, como las sociedades anónimas abiertas. Dichas normas, incorporadas a la legislación el año $2009,{ }^{49}$ son familia-

${ }^{49}$ Las normas que regulan las operaciones con partes relacionadas en las sociedades anónimas abiertas se encuentran en el título XVI de la Ley 18.046 del 22 de octubre de 1981, "Ley sobre sociedades anónimas"; las que fueron incorporadas por la Ley 20.382 del 20 de octubre de 2009, "Introduce perfeccionamientos a la normativa que regula los gobiernos corporativos de las empresas", ambas de la República de Chile. 
res tanto para organismos gubernamentales como para quienes asesoran a las entidades fiscalizadas, por lo que se facilita así la comprensión y aplicación de los nuevos mandatos por parte de la comunidad jurídica en un tema que es complejo.

Sería valioso que una nueva iniciativa legislativa adopte algunas de las ideas incorporadas en este proyecto de ley, especialmente, la creación de un organismo especializado de fiscalización, como la Superintendencia de Educación Superior; la regulación de transacciones entre las universidades y sus entidades relacionadas; y la imposición de un marco que regule la responsabilidad de los directores de universidades. Al diseñar e implementar dichas normas, habría que tomar en cuenta que, a diferencia de las grandes empresas, donde la relación de agencia se establece entre los accionistas y el directorio, en las organizaciones sin fines de lucro dicha relación se da entre la misión de la institución ( $y$, tal vez, entre los miembros del público a quienes la institución intenta beneficiar) y su directorio. ${ }^{50}$ Esta particular condición requiere la existencia de resguardos especiales, de manera de asegurar que las instituciones cumplan con sus respectivos fines.

Considerando los objetivos antes mencionados, y sobre la base de la experiencia que ha existido en la regulación de las sociedades anónimas abiertas chilenas, se describen a continuación principios que podrían inspirar una futura iniciativa legislativa tendiente a regular las transacciones entre las universidades y sus entidades relacionadas:

1. Requerimiento de contar con directores independientes. La independencia del directorio es un primer paso necesario si lo que se busca es un proceso de deliberación más transparente y exhaustivo. El requisito de independencia podría concebirse tanto como una pauta para todos los directores designados acerca de la conducta que de ellos se espera, como un requisito que exija que algunos de los directores de la universidad sean independientes de sus controladores o de cualquier

50 Para los efectos de este artículo, debe entenderse por "directorio" cualquier órgano colegiado en el que resida la dirección y administración superior de la universidad respectiva, cualquiera sea su designación (como "Consejo Superior Directivo", "Junta Directiva", "Consejo Directivo" u otra), y sin importar si la universidad se ha constituido como fundación o corporación. Por "director", en tanto, debe entenderse cualquier persona que haya sido designada para ocupar un lugar en dicho órgano. 
otra persona, entidad o grupo con capacidad para influir en los asuntos de la misma.

La primera parte de este requisito ya ha sido abordado en la Ley sobre Sociedades Anónimas. El artículo 39 de dicho cuerpo legal establece que "los directores elegidos por un grupo o clase de accionistas tienen los mismos deberes para con la sociedad y los demás accionistas que los directores restantes, no pudiendo faltar a éstos y a aquélla a pretexto de defender los intereses de quienes los eligieron". ${ }^{51}$ Esta declaración no existe en ninguna de las normativas que se aplican a las instituciones sin fines de lucro o en cualquier otra normativa referida a las universidades, aunque sí fue considerada por los autores del proyecto de ley. Adoptar un mandato de independencia como el anterior en una futura propuesta referida al gobierno universitario dejará en claro a los directores que sus deberes son para con la universidad, su misión y las personas a quienes ésta busca beneficiar, y no para con quienes los han designado o han promovido su designación.

La segunda parte del requisito de independencia encuentra también fundamento en la Ley sobre Sociedades Anónimas ${ }^{52}$ e, igualmente, fue considerado en el proyecto de ley. Este último establecía que el directorio de las universidades que no tengan carácter estatal debería estar integrado al menos por tres miembros independientes. Se entregaban, asimismo, reglas para determinar quiénes no se considerarían para estos efectos independientes, las que apuntaban, en general, a quienes por relaciones patrimoniales, fiduciarias o familiares compartan o hayan compartido intereses con los controladores de la universidad. Lo anterior es un enfoque razonable que, si está adecuadamente asociado con los quorum de aprobación, otorga a la institución una protección considerable al momento de contratar con entidades relacionadas.

Durante las discusiones en torno al proyecto de ley, se criticó que el requisito de contar con miembros independientes en el directorio de las universidades no realizaría la plenitud de sus objetivos, ya que para

${ }^{51}$ Ley 18.046 de 1981.

52 El artículo 50 bis de la Ley sobre Sociedades Anónimas establece que las sociedades anónimas abiertas que cumplan con ciertas condiciones de patrimonio bursátil y estructura accionaria deberán designar al menos un director independiente y un comité de directores, formado por tres directores, la mayoría de los cuales (o al menos uno de ellos, si no hubiera más) deberá ser independiente. Ver Ley 18.046 de 1981 . 
dichos directores podría ser muy difícil entender las repercusiones de las decisiones adoptadas por el directorio en la gestión de la universidad y, particularmente, en la educación que la universidad entrega a sus estudiantes. Esta crítica hace sentido si consideramos que en las sociedades comerciales se dispone usualmente de detallados indicadores financieros y de desempeño, y en las sociedades anónimas abiertas (por el interés general que tienen) dicha información es auditada y está sujeta al escrutinio de autoridades fiscalizadoras, operadores de mercados bursátiles, asesores financieros y el público en general. Todo lo anterior facilita la labor de los directores de sociedades. Sin embargo, cuando se trata de las universidades, por la naturaleza de los servicios que prestan, la evaluación de su desempeño es sumamente compleja, y el escrutinio al que está sometida la información financiera con la que se cuenta por parte de personas o entidades independientes de sus controladores, si lo hubiera, es limitado. ${ }^{53}$ Esto supondría una pesada carga para los directores independientes, quienes no tendrían, por sí solos, la autoridad para asignar recursos del directorio a la recopilación y análisis de información relevante relativa a la gestión de la universidad. Ello es especialmente importante en el caso de las transacciones con entidades relacionadas (por ejemplo, es probable que si una universidad compra materiales educativos a una entidad relacionada, a un director independiente le sería extremadamente difícil determinar si se está pagando un precio justo por ellos o evaluar su calidad y contribución al proceso de aprendizaje de los estudiantes que los utilizan). Debido a que estos problemas están íntimamente ligados a las características especiales de los servicios que las universidades entregan a la sociedad (cuya calidad se mide en el largo plazo), es esencial dotar a los directores independientes de las herramientas necesarias para evaluar las condiciones, el riesgo y los efectos de las decisiones que enfrentan los directorios universitarios.

Una vez más, la regulación de las sociedades anónimas entrega una valiosa solución, que no fue contemplada en el proyecto de ley.

${ }^{53}$ Según el artículo 114 del Decreto con Fuerza de Ley N. ${ }^{\circ} 2$ del Ministerio de Educación de 2010, las instituciones de educación superior que reciben aporte fiscal deben enviar anualmente al Ministerio de Educación la memoria explicativa de sus actividades y su balance. Las instituciones de educación superior de carácter privado que cuenten con aporte fiscal deben rendir cuenta al Ministerio de Educación sólo respecto de los fondos fiscales que hubieren recibido. Ver Decreto con Fuerza de Ley N. ${ }^{\circ} 2$ del Ministerio de Educación de 2010. 
Ésta consiste en requerir un presupuesto anual para uso exclusivo de los directores independientes (o más bien del comité que ellos integren, como se propone más adelante).$^{54}$ Ese presupuesto les entregaría la posibilidad de contratar los servicios de asesores en materias educativas, financieras, operacionales u otras, permitiéndoles así contar con una recomendación experta si estiman que ello es necesario o conveniente para emitir una opinión o un voto informado. El monto de dicho presupuesto anual podría determinarse por ley en relación con el patrimonio declarado por cada universidad.

2. Descripción de las transacciones con entidades relacionadas. Para efectos de identificar las transacciones con entidades relacionadas a una universidad, la ley debiera, en general, considerar aquellas transacciones en que intervengan de modo directo o indirecto la universidad y sus controladores, miembros, directores, ejecutivos principales o bien las personas naturales y jurídicas que se encuentran bajo una influencia relevante de cualquiera de las personas que califican en las categorías anteriores. En general, el proyecto de ley reconocía estos conceptos. No obstante, hay dos consideraciones que pueden otorgar protecciones adicionales para evitar los efectos indeseados de los conflictos de interés y producir mayor eficiencia.

En primer lugar, sería valioso que una futura propuesta tome en consideración que cada universidad enfrenta diferentes necesidades, desafíos y amenazas para el mejor funcionamiento de su gobierno. Cada directorio universitario es el órgano que puede evaluar dichas amenazas de manera más informada y con una visión más amplia de las necesidades de la institución. El posibilitar que los estatutos de cada universidad o el comité de directores independientes (cuyo establecimiento se propone más adelante), por resolución fundada, pudieran identificar contrapartes específicas para efectos de tratar las transacciones con ellas como transacciones con entidades relacionadas, constituiría una instancia de protección adicional. Lo anterior, porque podrían quedar bajo el proce-

${ }^{54}$ El artículo 50 bis de la Ley sobre Sociedades Anónimas establece, en su parte relevante, que "la junta ordinaria de accionistas determinará un presupuesto de gastos de funcionamiento del comité y sus asesores, el que no podrá ser inferior a la suma de las remuneraciones anuales de los miembros del comité, y éste podrá requerir la contratación de la asesoría de profesionales para el desarrollo de sus labores, conforme al referido presupuesto". Ver Ley 18.046 de 1981. 
dimiento de aprobación que describa la normativa situaciones que no hubieran sido previstas por los legisladores y que pudieran representar una amenaza para la independencia del directorio de la universidad..$^{55}$

En segundo lugar, debe reconocerse que a las universidades se les permite (y, desde una perspectiva práctica, requieren) obtener ganancias de sus actividades. Éstas pueden ser generadas directamente por su propia gestión o, bien, por actividades de sociedades en cuya propiedad la universidad participa. Existen muchas y variadas razones por las cuales una universidad podría crear o ingresar a la propiedad de otra entidad. Las universidades pueden buscar socios y participar en sociedades comerciales para explotar los resultados de sus investigaciones, prestar servicios de consultoría o incluso para otorgar a sus estudiantes la posibilidad de adquirir experiencia práctica en sus ámbitos de estudio a la vez que atienden necesidades sociales, a través de instituciones como hospitales o medios de comunicación social. ${ }^{56}$ Las distribuciones de excedentes que representan un flujo de fondos desde las entidades relacionadas en que la universidad participa hacia la universidad no deberían considerarse, en general, una transacción con entidades relacionadas para efectos de la ley. En ese caso, más que ingresar en una transacción particular, la universidad está obteniendo el retorno de sus propias actividades $\mathrm{y}$, salvo excepciones, dicho flujo de fondos no ocasionará perjuicios a la universidad. ${ }^{57,58}$

${ }^{55}$ Este principio ha sido considerado en el artículo 146 de la Ley sobre Sociedades Anónimas, que establece que se considerarán operaciones con partes relacionadas para efectos de la ley aquellas que establezcan los estatutos de la sociedad o fundadamente identifique el comité de directores, si lo hubiera. Ver Ley 18.046 de 1981.

${ }^{56}$ Deben distinguirse las actividades anexas al giro universitario (como consultoras, hospitales y medios de comunicación social), del giro propiamente universitario. No debe permitirse que entidades relacionadas a las universidades en las que participen terceros realicen actividades del giro propiamente universitario.

${ }^{57}$ Para una discusión más extensa sobre casos en que los flujos de fondos de sociedades relacionadas en que la universidad participa pueden causar perjuicios a esta última, y propuestas sobre su control, ver Valenzuela, "La prohibición", 31-33.

58 Bernasconi hace la distinción entre lo que denomina "la universidad como negocio" y "negocios de la universidad", siendo ilegítimos los primeros y legítimos los segundos. Ver Andrés Bernasconi, "Prohibición del lucro en las universidades: alcance y consecuencias", Temas de la Agenda Pública 62 (2013): 3, http://politicaspublicas.uc.cl/cpp/static/uploads/adjuntos_publicaciones/adjuntos publicacion. archivo adjunto.a4788f2afd30dd21.5061706572204ec2ba203632204c7563726f206 56e2045647563616369c3b36e205375706572696f722e706466.pdf/. 
En consecuencia, son las transacciones entre la universidad y entidades relacionadas distintas a las descritas en el párrafo anterior (vale decir, aquellas que no implican una distribución de excedentes a la universidad) las que encienden mayores luces de alerta y las que debieran activar el procedimiento de aprobación para transacciones con entidades relacionadas.

La fijación de las remuneraciones de los directores de las universidades es también un asunto cuya determinación, si fuera entregada al directorio, calificaría como una transacción con entidad relacionada a la universidad. Siendo éste el más delicado de todos los conflictos de interés (pues todos los miembros del directorio tendrían interés en el asunto), una alternativa para evadirlo es entregar la determinación de estas remuneraciones a los miembros de la universidad. Éste fue el camino adoptado por el proyecto de ley.

3. Declaración oportuna, completa y precisa de hechos relativos a posibles transacciones con entidades relacionadas. Los directores con interés deben abstenerse de tomar parte en las deliberaciones sobre esos asuntos. Debiera exigirse a los directores, ejecutivos principales, miembros de la universidad y cualquier otra persona que, según las circunstancias, tenga vínculos relevantes con esta última (como asesores, académicos u otros funcionarios) que, actuando de buena fe, pongan en conocimiento del comité de directores independientes según se explica más adelante-, de manera oportuna, completa y precisa, los hechos concernientes a una posible transacción con entidades relacionadas de la que tuvieren conocimiento, sea que tuvieren o no interés en dicha transacción. Los directores que por sus vínculos patrimoniales, fiduciarios o familiares tuvieren interés en una transacción con entidades relacionadas, deberían declarar oportunamente y de manera completa y precisa la naturaleza de su interés y, en adelante, deberían abstenerse de participar en cualquier deliberación o votación relacionada a dicha transacción. Los terceros relacionados a la universidad que tuvieren interés en la transacción debieran proporcionar de buena fe y de manera oportuna toda la información relevante para la transacción que pudiese requerir el directorio o el comité de directores independientes. 
4. Monto mínimo para gatillar la aplicación del procedimiento de aprobación de transacciones con entidades relacionadas. Una normativa eficiente debe tomar en cuenta que los directorios están llamados a tomar las decisiones sobre la gestión universitaria al más alto nivel. En consecuencia, el tiempo del directorio - actuando como órgano colegiado - así como el de cada uno de sus miembros debería estar reservado sólo para los asuntos más relevantes que atañen a la institución educativa, evitando que operaciones rutinarias queden sujetas a la aprobación del directorio. Un monto mínimo para gatillar la aplicación del procedimiento de aprobación de transacciones con entidades relacionadas, como el que aquí se propone, permitiría que el directorio se abocara al conocimiento sólo de aquellas transacciones con entidades relacionadas que, en atención a las circunstancias, sean más relevantes para la universidad. El monto mínimo de dos mil unidades de fomento (UF) propuesto por el proyecto de ley (el mismo que aplica a las operaciones con partes relacionadas de las sociedades anónimas abiertas y cerradas, según la Ley sobre Sociedades Anónimas) es útil para este fin. No obstante, un futuro proyecto podría también tomar en consideración que los recursos de que dispone cada universidad son diferentes y, por lo tanto, el impacto que una misma transacción específica tendría en los registros contables y financieros variará para cada universidad. De tal forma, además de un monto mínimo fijo de referencia, podría ser considerada la relevancia de una transacción con entidades relacionadas, en función del porcentaje que dicha transacción representa en el patrimonio de la universidad. Así, por ejemplo, sólo aquellas transacciones con entidades relacionadas cuyo precio exceda el 1 por ciento del patrimonio de la universidad quedarían sujetas al procedimiento de aprobación aquí propuesto. De conformidad con lo anterior, una transacción cuyo precio excediera el monto mínimo fijo de referencia, pero que no excediera un determinado porcentaje del patrimonio de la universidad, seguiría estando exenta del procedimiento de aprobación. Para evitar que transacciones que, no obstante no exceder un porcentaje mínimo del patrimonio de la universidad, por su monto, se estime que no debieran quedar exentas de las protecciones que otorga el procedimiento de aprobación propuesto, podría fijarse un monto máximo que determinaría la aplicación de dicho procedimiento en cualquier caso (en los artículos 44 y 147 de la Ley sobre Sociedades Anónimas se contempla 
para estos efectos un monto máximo de 20 mil UF). Las transacciones realizadas dentro de un período específico (por ejemplo, un año) en que exista identidad de partes u objeto deberían considerarse como una sola operación para efectos de aplicar los límites propuestos.

5. Transacciones deben realizarse en términos de mercado. Se debiera requerir que todas las transacciones con entidades relacionadas, sea que su valor supere o no los límites mínimos que determinan la aplicación del procedimiento de aprobación propuesto, se ajusten a condiciones de equidad similares a las que habitualmente prevalecen en el mercado al tiempo de su celebración. El comité de directores independientes (propuesto más adelante) debiera ser el órgano encargado de velar por el cumplimiento de este requisito. La condición mencionada fue incluida en el mencionado proyecto de ley y está inspirada en lo dispuesto en la Ley sobre Sociedades Anónimas. De manera similar, por ejemplo, en Estados Unidos (donde, según datos del año 2010, el sector sin fines de lucro representaba el 9,2 por ciento de los salarios pagados en el país, y en 2014 correspondía al 5,3 por ciento de su producto interno bruto), ${ }^{59}$ la New York Not-for-Profit Corporation Law (modificada en 2013 por la Non-Profit Revitalization Act) contempla, como condición principal para proceder con transacciones con entidades relacionadas, que el directorio de cada institución determine previamente que la transacción es justa, razonable y en el mejor interés de la institución al momento de la determinación. Se agrega, además, el mandato a los directores y miembros de la alta administración de la institución que tengan interés en la transacción de revelar de buena fe al directorio o comité correspondiente los hechos relevantes concernientes a su interés, y que dichas personas no podrán participar en las deliberaciones y votaciones relativas a la transacción. ${ }^{60}$

6. Opinión externa para las transacciones con entidades relacionadas que involucren inmuebles. Las transacciones con entidades relacionadas que involucran inmuebles son las más relevantes para las

${ }^{59}$ National Center for Charitable Statistics, "Quick Facts about Nonprofits", http://nccs.urban.org/statistics/quickfacts.cfm (accedida el 12 de abril de 2015).

${ }^{60}$ Ver New York Not-for-Profit Corporation Law $\$ 715$ y $\$ 715-A$, Estado de Nueva York, Estados Unidos. 
universidades, debido a su precio, los activos esenciales que los inmuebles representan para ellas y la probabilidad de que dichas transacciones sean utilizadas por sus controladores $\mathrm{u}$ otros miembros para obtener ganancias provenientes de las actividades universitarias, contraviniendo el espíritu de la ley. Para las transacciones con entidades relacionadas que involucren compraventa, arrendamiento o cesión del uso y goce de un inmueble de cualquier otra forma, se debiera requerir la opinión (en cuanto a precio y condiciones) de al menos una entidad especializada independiente, para así evitar la existencia de condiciones abusivas requeridas por las entidades relacionadas a la universidad. ${ }^{61}$

7. Informe previo elaborado por un comité de directores independientes. Las operaciones que califiquen como transacciones con entidades relacionadas deberían ser presentadas a un comité especial formado por directores de la universidad que tengan la calidad de independientes (y, como mínimo, por tres de ellos, si hubieran más). En las universidades estatales, este comité debería estar integrado exclusivamente por los miembros del directorio que hayan sido designados por el Presidente de la República (y que hacen, para estos efectos, las veces de directores independientes).

El comité propuesto debería estar a cargo de: (i) diseñar e implementar un sistema de reportes que facilite la detección temprana de operaciones que pudieran calificar como transacciones con entidades relacionadas (esta política podría también incluir la obligación de que los directores, con posterioridad a su designación y antes de asumir el cargo, entreguen al comité de directores independientes, o al organismo que éste designe, una nómina de las entidades con las que tienen una relación relevante y cualquier otra situación que, de acuerdo con su mejor saber y entender, pudiera dar lugar a un conflicto de interés, la que se renueve periódicamente hasta que abandonen su cargo); ${ }^{62}$ (ii) asegurar una amplia difusión de las situaciones que representan conflictos de interés y del sistema de reportes mencionado, entre los directores, ejecutivos principales, miembros de la universidad y otras personas que, por su posición, pudieren tener conocimiento de situaciones que

${ }^{61}$ Ver Williamson, "Universidad y lucro", 152-53.

${ }^{62}$ Ver New York Not-for-Profit Corporation Law §715-A, Estado de Nueva York, Estados Unidos. 
envuelvan posibles conflictos; (iii) evaluar todos los componentes de las potenciales transacciones con entidades relacionadas que lleguen a su conocimiento, como precio, frecuencia, relación con las condiciones de mercado y el impacto de la transacción para el mejor interés de la universidad; y (iv) preparar un informe al respecto para someterlo al conocimiento del directorio. Este informe incluiría la opinión individual de cada uno de los miembros del comité de directores independientes en cuanto a proceder o no con la transacción.

La New York Not-for-Profit Corporation Law (según fue modificada en 2013) dispone, con respecto a cualquier transacción que involucre un cierto tipo de instituciones sin fines de lucro (charitable corporations), en las que entidades relacionadas a ellas tengan un interés patrimonial sustantivo, que el directorio de dichas instituciones, antes de ingresar a la transacción, debe considerar, en la medida de lo posible, transacciones alternativas. ${ }^{63}$ Adoptar esta idea para una futura regulación chilena, exigiendo el análisis de transacciones alternativas con entidades no relacionadas al nivel del comité de directores independientes, requerirá que los miembros de ese comité necesariamente indaguen sobre cuál es el valor justo de mercado y justifiquen, con alternativas, por qué una transacción propuesta es en el mejor interés de la universidad. Naturalmente, el comité de directores independientes podría valerse para esta tarea de la opinión de asesores externos (haciendo uso de su presupuesto separado), si así lo estimara necesario o conveniente.

8. Aprobación por mayoría absoluta en dos instancias. Antes de que la universidad ingrese a una transacción con entidades relacionadas, debiera requerirse la aprobación por mayoría absoluta, tanto de los miembros del comité de directores independientes como del directorio (en este último caso, excluyendo a los miembros del comité de directores independientes, quienes ya se habrán pronunciado). Los directores con interés en la transacción debieran abstenerse de participar en las correspondientes deliberaciones y votaciones, pero se les debiera exigir que proporcionen de buena fe y oportunamente cualquier información adicional que pudiera requerir el directorio o el comité de directores independientes. El voto individual de cada uno de los miembros del co-

${ }^{63}$ Ver New York Not-for-Profit Corporation Law §715, Estado de Nueva York, Estados Unidos. 
mité de directores independientes debiera ser incluido en el informe que al efecto preparen para el directorio. De tal manera, si la transacción no obtiene la aprobación por mayoría absoluta de los miembros del comité de directores independientes, se consideraría que ésta ha sido rechazada y no sería necesaria la votación del directorio. Así se evitaría que este último se aboque a discusiones sobre temas complejos que podrían no contar ex ante con la aprobación del comité de directores independientes. Si la mayoría absoluta de los directores no independientes estuvieren involucrados en la posible transacción, siguiendo la regla aplicable a las sociedades anónimas abiertas, se debiera exigir la aprobación unánime de los directores que no tengan interés ${ }^{64}$ (además de la aprobación previa por el comité de directores independientes). Si todos los directores no independientes tuvieren interés en la posible transacción, o todos excepto uno, el voto de los directores independientes debiera dirimir el asunto. En esta situación altamente conflictiva, parece adecuado requerir, de manera excepcional, la aprobación unánime del comité de directores independientes. El proyecto de ley consideraba un mecanismo similar, aunque simplificado, de aprobación, exigiendo el voto favorable de la mayoría de los directores no interesados y, adicionalmente, el voto favorable de la mayoría de los directores independientes o de aquellos designados por el Presidente de la República, en el caso de las universidades estatales. No obstante, tal propuesta no contemplaba la creación de un comité de directores independientes y, de este modo, asumía que el voto de los directores no independientes y no interesados, y el de los directores independientes, sería simultáneo.

Es importante que una descripción detallada de las condiciones de las operaciones aprobadas, los antecedentes que se hayan considerado, las deliberaciones y los detalles de los procesos de votación del comité de directores independientes y del directorio queden registrados en las actas que se levanten de las respectivas sesiones.

9. Divulgación ex post a los miembros de la universidad y a las autoridades regulatorias correspondientes. Debiera exigirse que todas las transacciones con entidades relacionadas que sean aprobadas conforme al procedimiento propuesto sean informadas periódicamente

${ }^{64}$ Ver artículo 147 de la Ley 18.046 de 1981. 
por el directorio a los miembros de la universidad y a las autoridades regulatorias correspondientes (como la Superintendencia de Educación Superior cuya creación se proponía en el proyecto de ley). Dicho informe debería incluir, para cada transacción con entidades relacionadas aprobada en el período, información detallada sobre la transacción y las causas del conflicto de interés, los resultados de las respectivas votaciones y quienes se hayan abstenido de votar, y los antecedentes que se hayan tomado en cuenta para la aprobación de la transacción. Una copia de las actas de las sesiones del directorio y del comité de directores independientes debiera acompañarse a este informe. Para efectos de la presentación de estos informes, podría crearse un formulario único distribuido por la autoridad, el que facilitaría el procesamiento de toda la información relevante por parte de los miembros de la universidad y de la autoridad, haciendo, de tal manera, más efectivas las instancias de revisión.

10. El incumplimiento de los requisitos previos no afectará la validez de la transacción, pero otorgará el derecho a perseguir las responsabilidades que correspondan. El principio de que las transacciones con entidades relacionadas que se realicen sin cumplir con los requisitos específicos para esas operaciones no sean inexistentes o inválidas es reconocido tanto en la Ley sobre Sociedades Anónimas como en el proyecto de ley. Este principio reconoce que las entidades relacionadas, las que no necesariamente están bajo un control común con (o ejercen una influencia relevante sobre) la parte que incurrió en la infracción, pueden haber confiado en la transacción y es así razonable dejarlas indemnes de una infracción en la que (al menos de manera directa) no participaron. Sin embargo, para hacer efectivos los resguardos que persigue el procedimiento propuesto, cualquier infracción al mismo debiera otorgar a los miembros de la universidad, a los directores disidentes (aquellos que han dejado constancia en actas de su oposición a la transacción) y a las autoridades regulatorias correspondientes (actuando de oficio o a petición de parte) el derecho de perseguir, a nombre de la universidad, la responsabilidad civil de los directores infractores (aquellos que hubieren concurrido a la aprobación de la transacción en contravención al procedimiento establecido o que negligentemente hubieren descuidado su aplicación) por los menoscabos que hubieren causado a la univer- 
sidad. Lo anterior, sin perjuicio de las sanciones administrativas que pudieren aplicarse por la autoridad.

Si la transacción no fue aprobada de acuerdo con el procedimiento de aprobación propuesto, debiera corresponder a los presuntos directores infractores probar que no correspondía su aplicación o, al menos, que la transacción se realizó de buena fe, contando con información adecuada, en condiciones de equidad similares a las que habitualmente prevalecen en el mercado y que, razonablemente, se preveía beneficiosa para los intereses de la universidad al tiempo de su ejecución (evitando sesgos retrospectivos). En ese caso, aun cuando los directores satisfagan el estándar de prueba propuesto y no sean responsables de los perjuicios causados, igualmente podrían ser objeto de la aplicación de sanciones administrativas por la autoridad, si hubieren incurrido en alguna infracción a sus deberes fiduciarios. Si, por el contrario, la transacción fue aprobada en conformidad con el procedimiento propuesto, la carga de la prueba debiera recaer sobre el demandante, quien tendrá que demostrar que ha existido injusticia en el proceso (por ejemplo, omisión o defecto de las revelaciones de información procedentes, consideración errónea respecto de los directores no interesados en la transacción, falta de imparcialidad en la opinión de asesores externos o incumplimiento de deberes fiduciarios) o en relación con el precio (que hubieran discrepancias relevantes con las condiciones de equidad que habitualmente prevalecen en el mercado), ${ }^{65}$ y que, como consecuencia de lo anterior, ha existido perjuicio para la universidad. Así, el cumplimiento del procedimiento de aprobación propuesto serviría como una presunción simplemente legal (esto es, que admite prueba en contrario) de que el proceso de aprobación fue adecuado, así como justo el precio de la transacción.

Siguiendo el principio general de la responsabilidad de los directores de sociedades anónimas y lo indicado en el proyecto de ley, los directores infractores debieran responder solidariamente por los perjuicios causados a la universidad.

65 Ésta es una aplicación del estándar de derecho societario estadounidense conocido como entire fairness, el que permite la exención de responsabilidades cuando tanto el procedimiento de aprobación de una transacción como su precio han sido justos. Ver Weinberger v. UOP, INC., 457 A.2d 701 (Del. 1983). 


\section{UN COMPLEMENTO NECESARIO: PERFECCIONAR LOS DEBERES FIDUCIARIOS DE LOS DIRECTORES DE LAS UNIVERSIDADES}

El rol de quienes sirven como directores en instituciones sin fines de lucro difiere sustancialmente de lo que se espera de los directores en las sociedades (u organizaciones con fines de lucro). En las sociedades en que el capital está representado por acciones, la relación de agencia se establece entre sus accionistas, como mandantes o principales, y su directorio, como mandatario o agente. En las instituciones sin fines de lucro la relación de agencia se establece entre la misión de la institución y, quizás (como se ha sugerido), los miembros del público a quienes la institución intenta beneficiar, como mandantes o principales, y su directorio, como mandatario o agente. Según Goldschmid, "los directores y ejecutivos de las organizaciones con fines de lucro están principalmente ocupados de la maximización de las ganancias en el largo plazo. Si bien los directores y ejecutivos de las instituciones sin fines de lucro tienen los temas económicos presentes, están principalmente ocupados del cumplimiento efectivo de la misión de esas instituciones". ${ }^{66}$ Adicionalmente, a diferencia de los directores de sociedades, puede que los directores designados en las instituciones sin fines de lucro tengan escasa o ninguna experiencia de negocios, que hayan sido elegidos para el cargo por motivos completamente ajenos a su capacidad para obtener términos provechosos o equitativos en una transacción y que se muestren reacios a gastar fondos de la institución en asesores externos. Además, considerando que, por regla general, no son remunerados, dispondrán de un tiempo limitado para dedicar a las instituciones en que sirven. Finalmente, a diferencia de lo que ocurre en las sociedades anónimas, en las instituciones sin fines de lucro no existe una protección análoga a aquella que otorga la aprobación o ratificación de un acto por una junta de accionistas, ni tampoco, como ocurre en las sociedades anónimas abiertas, su gestión está sometida al escrutinio de una autoridad regulatoria especializada y, en efecto, del público general, a través de la información que se les exige difundir. ${ }^{67}$ Debido a estas característi-

${ }^{66}$ Harvey J. Goldschmid, "Fiduciary Duties of Nonprofit Directors and Officers: Paradoxes, Problems, and Proposed Reforms", Journal of Corporation Law 23 (Summer 1998): 641.

${ }^{67}$ Ibídem, 637. 
cas propias de los directorios de las instituciones sin fines de lucro, no sería prudente esperar que las protecciones que otorga el procedimiento propuesto en la sección anterior para los casos de conflictos de interés sean efectivas sin que exista, en primer lugar, un marco de normas que regulen los deberes fiduciarios de quienes sirven en los directorios de las universidades, ni, en segundo lugar, una entidad fiscalizadora con atribuciones y recursos adecuados.

La legislación chilena actual no contempla normas específicas sobre los deberes fiduciarios que aplican a los directores de las universidades. Las únicas reglas existentes son aquellas contenidas en el título XXXIII del Libro I del Código Civil, aplicables a las personas jurídicas sin fines de lucro, y de manera supletoria a las universidades. Estas reglas son, sin embargo, considerablemente acotadas.

Una futura normativa sobre el gobierno de las universidades debería contemplar, además de reglas para la resolución de conflictos de interés, normas específicas relativas a los deberes fiduciarios de los directores. Los deberes de cuidado y de lealtad deberían adaptarse a las características únicas de los directorios de instituciones sin fines de lucro y, especialmente, a la realidad de las universidades chilenas (directorios que constan, al menos en parte, de expertos en educación, volumen considerable de transacciones con entidades relacionadas y necesidad de recaudar fondos en un entorno de escasa filantropía y falta de recursos públicos destinados a las universidades privadas).

La legislación chilena ha equiparado históricamente el deber de cuidado con el deber de actuar con la diligencia que los hombres emplean ordinariamente en sus negocios propios. Éste es el estándar actualmente vigente en el contexto de las sociedades anónimas, según la Ley sobre Sociedades Anónimas, y también en el contexto de las personas jurídicas sin fines de lucro, conforme al título XXXIII del Libro I del Código Civil. ${ }^{68}$ Sin embargo, este estándar no pareciera ser enteramente apropiado, ya que no toma en consideración las circunstancias particulares de los directores de organizaciones sin fines de lucro. Al enmarcar el alcance del deber de cuidado, podría ser útil considerar el enfoque de organizaciones internacionales y legislaciones extranjeras. La OECD, en sus recomendaciones de gobierno corporativo, dispone que el deber de cuidado "requiere a los miembros del directorio actuar de una manera plenamente

${ }^{68}$ Ver Ley 18.046 de 1981 y Código Civil de Chile, artículos 44 y 551-2. 
informada, de buena fe y con la debida diligencia y cuidado. En algunas jurisdicciones hay un estándar de referencia que es el comportamiento que una persona razonablemente prudente habría tenido en circunstancias similares". ${ }^{69}$ En Estados Unidos, precisamente, jurisdicción con vasta experiencia en gobiernos corporativos, el deber de cuidado de los directores se ha regulado tradicionalmente considerando lo que una persona ordinariamente prudente habría hecho en "circunstancias similares" y en una "posición semejante". ${ }^{70}$ Según Goldschmid,

los términos "circunstancias similares" y "posición semejante" otorgan flexibilidad, permitiendo que factores como la naturaleza de la institución sin fines de lucro, su tamaño y complejidad, la magnitud de cualquier problema y el rol individual de un director o ejecutivo, sean tomados en cuenta al juzgar si el director o ejecutivo han actuado con cuidado razonable. ${ }^{71}$

Una aproximación como ésta no es actualmente considerada por la normativa chilena, que se centra, en cambio, en la diligencia y cuidado del hombre medio. Sin embargo, la elevada confianza depositada en los directores, en tanto administradores de un patrimonio ajeno, requiere de ellos una responsabilidad especial, que excede la de la diligencia y cuidado del hombre medio. Este principio cobra aún mayor vigor en las instituciones sin fines de lucro, donde la fiscalización de terceros es considerablemente más acotada que en el ámbito societario (donde los socios o accionistas ejercen un rol supervisor). Un enfoque ajustado a las circunstancias del caso y que, sobre todo, reconozca la elevada confianza depositada en quienes sirven como agentes fiduciarios como el descrito sería una contribución útil en cualquier intento futuro de legislar sobre el estándar de conducta de los directores de instituciones sin fines de lucro.

No obstante, el uso de conceptos como "circunstancias similares", "posición semejante" u otros del tipo resulta actualmente ajeno a la

${ }^{69}$ OECD, "Principles of Corporate Governance", 2004, 59, http://www.oecd. org/corporate/ca/corporategovernanceprinciples/31557724.pdf/.

${ }^{70}$ Ver American Law Institute, Principles of Corporate Governance: Analysis and Recommendations, Volume 1 (Saint Paul, Minnesota: American Law Institute Publishers, 1994), 133.

${ }^{71}$ Goldschmid, "Fiduciary Duties”, 642. 
legislación chilena, incluso en el contexto de la regulación societaria. Respecto del estándar de cuidado que sí resulta aplicable tampoco existe suficiente jurisprudencia u opiniones que sirvan de guía sobre su aplicación a casos concretos, especialmente en lo referido a instituciones sin fines de lucro. Esta falta de experiencia no debiera disuadirnos de realizar esfuerzos por mejorar nuestra regulación actual en materia de deberes fiduciarios, introduciendo, quizás, conceptos que vayan en línea con los antes mencionados. Si bien el mejor manejo de estos conceptos sólo lo traerá la experiencia, hay hechos objetivos que proporcionan información acerca de la diligencia o negligencia con la que actúa un director al tomar una decisión, y que indudablemente arrojan luces para hacer una comparación con lo esperable en circunstancias similares. La regularidad con que un director asiste a las reuniones de directorio, sus opiniones registradas en las actas de dichas reuniones, un registro de las asesorías independientes que se han solicitado (lo que es especialmente relevante para los directores independientes), el diseño e implementación de códigos de conducta ética al interior de la institución, la creación de mecanismos confidenciales para el reporte de situaciones de riesgo o irregularidades que se detecten al interior de ella y, en general, cualquier evidencia acerca de los esfuerzos del directorio, y de cada uno de sus miembros en forma particular, por actuar de manera competente, de buena fe y en el mejor interés de la institución, constituirán instancias valiosas para evaluar potenciales responsabilidades. ${ }^{72}$ Otros factores debieran también considerarse, como el tamaño y complejidad de la institución, sus circunstancias particulares, los recursos que la institución pone a disposición de los directores para ocuparse de determinadas materias, la relevancia del asunto para la institución y

${ }^{72}$ En este sentido, una iniciativa particularmente destacable es la Norma de Carácter General N. ${ }^{\circ} 341$, emitida por la Superintendencia de Valores y Seguros, con fecha 29 de noviembre de 2012. En ella se requiere a las sociedades anónimas abiertas que anualmente entreguen a esa superintendencia y al público información sobre sus prácticas de gobierno corporativo, incluyendo, entre otras materias, la forma de funcionamiento del directorio y los tratamientos de conflictos de interés. Esta norma fue reemplazada por la Norma de Carácter General N. ${ }^{\circ} 385$, emitida por la misma superintendencia, con fecha 8 de junio de 2015, la que sigue la línea de su predecesora, pero amplía los requerimientos de información. Ver Superintendencia de Valores y Seguros de Chile, Norma de Carácter General N. ${ }^{\circ} 341,29$ de noviembre de 2012, y Superintendencia de Valores y Seguros de Chile, Norma de Carácter General N. ${ }^{\circ} 385,8$ de junio de 2015. 
qué tan predecibles eran los resultados indeseados al tiempo en que se tomó una decisión (cuidando distinguir meros errores de juicio al tomar una decisión de negocios, de manifiesta falta de atención o negligencia). Una vez que se ha recogido y procesado esta información, corresponderá a los tribunales decidir si los esfuerzos colectivos e individuales desplegados por los directores han sido los razonablemente adecuados (de conformidad al estándar propuesto) para evitar la existencia de las consecuencias indeseadas.

En cuanto al deber de lealtad, los deberes de los directorios universitarios "no pueden ser otros que los de cautelar el interés que la corporación o la fundación universitaria declaró servir al momento de constituirse y no los intereses de los controladores". ${ }^{73}$ Principios como los considerados en la propuesta de un procedimiento para la aprobación de transacciones con entidades relacionadas otorgan una guía que esclarece cómo debe esperarse que actúen los directores frente a una situación de conflicto de interés. Así, debiera hacerse hincapié en la divulgación oportuna, completa y precisa de cualquier potencial conflicto de interés que pudiere afectar a la universidad, la exclusión de los directores afectados por el conflicto de la toma de decisiones y, como siempre, la buena fe. En cualquier caso, la aplicación de todos estos estándares requiere de una cuidadosa evaluación imparcial de las circunstancias específicas de cada caso.

Además de la existencia de un marco de normas específicas, considerando las acotadas instancias de rendición de cuentas de las instituciones sin fines de lucro, se hace imprescindible la creación de una entidad especializada que fiscalice la actividad de las universidades. Dicha entidad podría también tener a su cargo las demás instituciones de educación superior. Ella debiera depender del Ministerio de Educación, tener personalidad jurídica y patrimonio propio, y contar con atribuciones y recursos apropiados para el cumplimiento de sus funciones. Respecto de las universidades, en especial, debiera estar a su cargo la recepción y revisión de información periódica que se les requiera (incluyendo información financiera y sobre transacciones con entidades relacionadas) y el desarrollo de procesos de investigación respecto de irregularidades observadas y denuncias recibidas, pudiendo imponer sanciones y multas a las personas que resulten responsables.

${ }^{73}$ Ver Peña, "La universidad y el lucro”, 134. 


\section{LA LEGISLACIÓN COMO HERRAMIENTA PARA ATRAER TALENTO A LOS GOBIERNOS UNIVERSITARIOS}

La existencia de un marco regulatorio específico y una entidad de fiscalización especializada son cruciales para el buen funcionamiento del sistema universitario. Sin perjuicio de lo anterior, la legislación debiera ser diseñada tomando en cuenta la extraordinaria importancia que los directorios universitarios tendrán en la educación de futuras generaciones. De ahí que exista una imperiosa necesidad de incentivar a personas con conocimientos y experiencia a participar en ellos. En el cumplimiento de ese propósito, la legislación tendrá un rol crucial.

La mención expresa en el proyecto de ley de la posibilidad de que los directores universitarios sean remunerados (lo que es contrario a la regla general de las personas jurídicas sin fines de lucro, sin perjuicio de que los estatutos de las universidades pueden modificarlo) es, en efecto, un primer avance en reconocer la importancia de incentivos para que personas con potencial para hacer contribuciones valiosas acepten el cargo. Sin embargo, una nueva propuesta legislativa podría ir un paso más allá, disponiendo que los directores universitarios serán remunerados, a menos que los estatutos de la universidad dispongan expresamente lo contrario. Para los miembros del comité de directores independientes, en atención a las responsabilidades especiales que sobre ellos recaerían, la ley podría disponer una remuneración adicional en proporción a aquélla recibida por los demás miembros del directorio. ${ }^{74}$ Para evitar los serios conflictos de interés que implica la fijación de las remuneraciones de los directores universitarios por el propio directorio de la universidad, esta determinación, siguiendo el proyecto de ley, debiera quedar entregada a los miembros de la universidad, y fijarse en consideración "a las responsabilidades y dedicación requeridas por la función y a las condiciones habituales de mercado a la fecha correspondiente". ${ }^{75}$

${ }^{74}$ Dispone el artículo 50 bis de la Ley sobre Sociedades Anónimas, en su parte relevante, que "los directores integrantes del comité serán remunerados. El monto de la remuneración será fijado anualmente en la junta ordinaria de accionistas, acorde a las funciones que les corresponde desarrollar, pero no podrá ser inferior a la remuneración prevista para los directores titulares, más un tercio de su monto". Ley 18.046 de 1981.

${ }^{75}$ Ver Presidencia de la República, "Superintendencia de Educación Superior", 36 . 
Debe tenerse presente que, incluso en la actualidad, los directores de instituciones sin fines de lucro pueden verse obligados a responder con su propio patrimonio por las consecuencias perjudiciales de sus decisiones en el cargo. Ello cobra todavía mayor importancia para el caso de las universidades, si se apunta a tener una entidad de fiscalización especializada que ejerza un control activo y tenga la facultad de imponer sanciones y multas sobre los directores de dichas instituciones. Para que la existencia de controles activos y el riesgo de sanciones y multas no desincentive a personas idóneas para participar en directorios universitarios, es preciso utilizar herramientas legislativas que, sin obstar a la efectividad de los controles, provean incentivos suficientes para que esas personas se sumen a los distintos proyectos.

El desafío de mantener sistemas efectivos de control y al mismo tiempo generar incentivos para la atracción de talentos es un problema común en las naciones desarrolladas, y, sin duda, en Chile se debe enfrentar la aparición cada vez más frecuente de denuncias sobre irregularidades e imposición de sanciones en los gobiernos corporativos de sociedades abiertas a la inversión pública. Así, la tendencia actual en las regulaciones societarias de países con experiencia en este fenómeno es otorgar a quienes sirven en directorios cuánto alivio de responsabilidad sea en derecho posible, en la medida en que los directores actúen de buena fe, debidamente informados, en una creencia razonable de que su actuación es en el mejor interés de la organización, y no hayan incurrido en infracciones a su deber de lealtad. Dichas jurisdicciones han desarrollado exhaustivos sistemas de resguardos contra la responsabilidad civil de los directores, que, con el tiempo, se han transformado en herramientas esenciales para la atracción de talento en sus organizaciones y el manejo del riesgo en sus economías. ${ }^{76}$ Como resulta evidente, una

${ }^{76}$ La regulación de sociedades del Estado de Delaware (donde una amplia mayoría de las más grandes sociedades de Estados Unidos se encuentra constituida), por ejemplo, permite que las sociedades allí creadas incluyan en sus estatutos renuncias a ejercer acciones contra sus directores por las infracciones de éstos a su deber de cuidado (lo que ha sido adoptado por cerca del 90 por ciento de las sociedades constituidas en dicho Estado), indemnizaciones a sus directores por su responsabilidad en actos culposos y reembolsos o adelantos a sus directores por las expensas legales en que incurran en la defensa de las demandas que enfrenten por infracciones a sus deberes. Además, dispone la ley que dichas sociedades pueden contratar seguros de responsabilidad civil para sus directores y ejecutivos a costa de la sociedad respectiva (lo que en la práctica casi siempre hacen). Estos mecanismos 
legislación que favorezca el desarrollo de un sistema universitario moderno, transparente y al mismo tiempo abierto a los mejores talentos de nuestra sociedad debe necesariamente hacerse cargo de estos desafíos.

En ese contexto, debido a la complejidad y tamaño de las universidades modernas, es muy importante que se reconozca la posibilidad de que sus directores, actuando de buena fe, tomen decisiones en base a la información obtenida de instancias diseñadas, justamente, para asistirlos en su función directiva. ${ }^{77}$ Así, un directorio que efectivamente dedique su tiempo a las decisiones más relevantes del quehacer universitario debiera implementar procedimientos y programas internos para el manejo de determinados asuntos (como, por ejemplo, comités con tareas específicas, designados por el directorio e integrados por funcionarios de la universidad) y recurrir, cuando lo estime conveniente, al servicio de asesorías especializadas externas (sea en materias educacionales, financieras, legales, laborales, de marketing u otras). Contar con un presupuesto anual separado para uso exclusivo de los miembros del comité de directores independientes, como se ha propuesto, permitiría que esos directores, especialmente, pudieran beneficiarse de esas asesorías. De tal manera, las decisiones que tomen en base a la información obtenida de procedimientos y programas internos debiera contribuir a aliviar su responsabilidad, siempre que los procedimientos y programas hayan sido cuidadosamente implementados, que su buen funcionamiento sea monitoreado por el directorio y que los directores actúen de buena fe. Lo mismo debiera aplicar respecto de las asesorías externas, en la medida en que éstas sean cuidadosamente seleccionadas (considerando su precio y experiencia), los prestadores mantengan una buena reputación en el mercado relevante y los directores actúen de buena fe.

Otra herramienta que puede ser también una manera eficaz para incentivar la participación de expertos valiosos en los directorios de las universidades es la utilización de seguros de responsabilidad civil para los directores. Estos seguros tienen una alta popularidad en el

de protección, en general, excluyen casos en que los directores no hayan actuado de buena fe o hayan incurrido en faltas a su deber de lealtad. Las disposiciones anteriores son también aplicables a las corporaciones sin fines de lucro constituidas en el Estado de Delaware, por lo que éstas también pueden hacer uso de las prerrogativas mencionadas. Ver Delaware General Corporation Law §102(b)(7) y §145, Estado de Delaware, Estados Unidos.

77 Ver Goldschmid, "Fiduciary Duties", 643. 
ámbito societario moderno y son cada vez más utilizados en Chile por las sociedades anónimas abiertas. ${ }^{78}$ Además, son muy comunes en el sector sin fines de lucro, incluyendo universidades, en países donde ese sector es prominente. Su cobertura, en general, comprende los costos asociados a defensas judiciales y condenas por infracciones al deber de cuidado de los directores, excluyendo, por lo general, casos de fraude o dolo e infracciones al deber de lealtad (como casos de enriquecimiento injusto). Vale decir, quedan excluidas de la cobertura las esferas más sensibles de la condición fiduciaria por la que los directores responden.

Si bien es cierto que la utilización de estos seguros conlleva un riesgo moral (pues los directores saben que las eventuales sanciones que podrían recibir serán, cuanto menos, moderadas a causa de la cobertura), dichos riesgos deben contrapesarse con los efectos ex ante que producen los seguros en el comportamiento de los individuos. La implementación de estos seguros no sólo contribuiría a que los posibles directores aceptaran designaciones para el cargo, sino que también los animaría a superar aversiones al riesgo al tomar decisiones que competen a la universidad y que pueden, con el tiempo, ser tremendamente provechosas (por ejemplo, al momento de atraer nuevos docentes, comprar un terreno para un nuevo campo de deportes, invertir en equipos para laboratorios, adquirir una colección de libros para las bibliotecas universitarias o iniciar el desarrollo de proyectos en lugares distantes). La legislación puede utilizarse como punto de partida para movilizar a las universidades a seguir esta iniciativa, otorgándoles discreción para que éstas contemplen a nivel estatutario la contratación y financiamiento de estos seguros para sus directores. ${ }^{79}$

Replicar estas ideas en un proyecto futuro sería sumamente valioso. Ellas reconocen la importancia del propósito de incentivar a

${ }^{78}$ Según una nota publicada en Economía y Negocios Online en septiembre de 2014, para entonces más del 80 por ciento de las empresas del IPSA y no menos del 40 por ciento de las empresas del IGPA había contratado seguros de responsabilidad civil para directores y ejecutivos. Ver "Sube demanda por seguros para directores tras conflictos corporativos", http://www.economiaynegocios.cl/noticias/noticias. asp?id=123303 (accedida el 16 de abril de 2015).

${ }^{79}$ El costo de estos seguros en Estados Unidos y Europa, por su alta popularidad, es relativamente bajo. Sin embargo, como es natural, las condiciones de la oferta de este producto en Chile para las instituciones sin fines de lucro (y las universidades, en particular) dependerán del interés de las compañías de seguro locales y las primas que éstas estén dispuestas a aceptar por la cobertura ofrecida. 
personas con conocimientos, experiencia, visión y capacidades para participar en los directorios de las universidades, sin menoscabar la efectividad de controles activos sobre los gobiernos universitarios y el fin último de la regulación: mejorar la calidad de nuestra educación superior.

\section{CONCLUSIONES}

La prohibición a los fines de lucro que la legislación chilena impone a las universidades desde 1981 condicionó de manera importante la forma en que estas instituciones se han desarrollado hasta la actualidad. Si bien no existe claridad sobre las razones que pudo haber considerado el legislador para imponer la prohibición, las particulares condiciones del servicio que entregan las universidades, principalmente generadas por asimetrías de información, hacen que una prohibición a los fines de lucro sea, cuanto menos, deseable.

Cuando los legisladores chilenos sentaron las bases de la legislación que, hasta la actualidad, gobierna a las universidades, no se contemplaron normas sobre el tratamiento de los conflictos de interés que pudieran afectarlas. Así, la legislación ha dejado espacio para que, por la vía de transacciones con entidades relacionadas, se causen perjuicios a las universidades. Con todo, las transacciones con entidades relacionadas, cuando son adecuadamente administradas y sujetas a controles independientes, pueden ser eficientes y útiles para los intereses de esas instituciones. En efecto, durante las últimas décadas, las transacciones con entidades relacionadas han sido fundamentales para el financiamiento, crecimiento y desarrollo de las universidades chilenas, lo que no quita que hayan podido existir abusos. Esto lleva a la conclusión de que, en vez de prohibir las transacciones con entidades relacionadas, es más eficiente y menos costoso regularlas de una forma efectiva.

En este artículo se proponen diez principios que pueden servir como marco para una futura regulación de las transacciones entre las universidades y sus entidades relacionadas. Éstos apuntan a crear un proceso informado de toma de decisiones, con la independencia como valor fundamental. Principios como los propuestos, recogidos parcialmente en un proyecto de ley retirado del Congreso a comienzos de 2014, podrían inspirar nuevos intentos legislativos que apunten a salva- 
guardar la transparencia, equidad y buena fe que se espera en el funcionamiento de nuestras universidades, así como un cumplimiento íntegro de su prohibición al reparto de excedentes.

Los principios referidos sólo lograrán una efectividad plena en la medida en que, conjuntamente, los deberes fiduciarios de quienes integran los directorios de las universidades sean debidamente regulados. Se hace necesario que el estándar de conducta impuesto reconozca la elevada confianza depositada en los directores universitarios, quienes administran un patrimonio ajeno enfrentando instancias de supervisión acotadas. Asimismo, la aplicación exitosa de estas protecciones y otras normas requiere de la creación de una entidad de fiscalización especializada, con atribuciones y recursos adecuados para llevar adelante un rol de control activo.

Con todo, es de la mayor importancia que cualquier regulación sea cuidadosamente diseñada, al mismo tiempo, para proteger el propósito de incentivar a personas con experiencia y talento a servir en los directorios de universidades. Alternativas que pueden ayudar a lograrlo son disponer expresamente en la ley que los directores de universidades recibirán una justa remuneración por sus servicios y, siguiendo el ejemplo de países desarrollados, establecer mecanismos que alivien la responsabilidad de los directores universitarios cuando éstos hayan actuado de buena fe, debidamente informados, en una creencia razonable que obran en el mejor interés de la organización y en cumplimiento, al menos, de su deber de lealtad. Medidas concretas que pueden producir este efecto son reconocer legislativamente resguardos para aquellos directores que actúan en base a antecedentes proporcionados por instancias de asesoría (en la medida en que los responsables sean diligentemente seleccionados) y la posibilidad de que las universidades contemplen en sus estatutos la contratación de seguros de responsabilidad civil para sus directores, los que tienen amplio uso en el ámbito societario.

Un marco regulatorio que considere las eficiencias que aportan las transacciones con entidades relacionadas y entregue principios para un tratamiento justo de las mismas; promueva una fiscalización activa hacia las universidades por una autoridad con facultades adecuadas; y reconozca las particulares condiciones y necesidades de los directorios de organizaciones sin fines de lucro involucradas en la educación superior sería un aporte sustancial para mejorar la calidad de la educación 
entregada a los estudiantes y fomentaría un servicio más pleno del irreemplazable rol que tienen las universidades en el desarrollo del país.

\section{BIBLIOGRAFÍA CITADA}

\section{Textos:}

American Law Institute. 1994. Principles of Corporate Governance: Analysis and Recommendations, Volume 1. Saint Paul, Minnesota: American Law Institute Publishers.

Bernasconi, Andrés. 2013. "Prohibición del lucro en las universidades: alcance y consecuencias." Temas de la Agenda Pública 62. http://politicaspublicas.uc.cl/ cpp/static/uploads/adjuntos_publicaciones/adjuntos_publicacion.archivo_ adjunto.a4788f2afd30dd21.5061706572204ec2ba203632204c7563726f20656 e2045647563616369c3b36e205375706572696f722e706466.pdf/.

Bernasconi, Andrés \& Fernando Rojas. 2004. Informe sobre la educación superior en Chile: 1980-2003. Santiago: Editorial Universitaria.

Beyer, Harald. 2011. "La discusión sobre el lucro: ¿acento correcto?” Revista Capital, 18 de octubre. http://www.brunner.cl/?p=2235/.

—. 2013. "Una agenda para la educación superior.” Documento de Trabajo 390, Centro de Estudios Públicos. http://www.cepchile.cl/dms/archivo_5235_3352/ HBeyer_presentacion.pdf/.

Brunner, José Joaquín \& Cristóbal Villalobos. 2014. Políticas de educación superior en Iberoamérica, 2009-2013. Santiago: Ediciones Universidad Diego Portales.

Deming, David J., Claudia Goldin \& Lawrence F. Katz. 2011. "The For-Profit Postsecondary School Sector: Nimble Critters or Agile Predators?" Working Paper 17710, National Bureau of Economic Research. http://www.nber.org/ papers/w17710.pdf/.

Fishman, James J. \& Stephen Schwarz. 1995. Cases and Materials on Nonprofit Organizations. New York: Foundation Press.

Fontaine, Arturo. 2012. "Lucro, universidad y filantropía." Estudios Públicos 128: 157-173.

Goldschmid, Harvey J. 1998. "Fiduciary Duties of Nonprofit Directors and Officers: Paradoxes, Problems, and Proposed Reforms." Journal of Corporation Law 23 (summer): 631-653.

Kinser, Kevin. 2011. "The Rise and Fall of For-Profit Higher Education." The Nelson A. Rockefeller Institute of Government. http://www.rockinst.org/ observations/kinserk/2011-08-for-profit_higher-ed.aspx/.

OECD. 2004. "Principles of Corporate Governance." http://www.oecd.org/ corporate/ca/corporategovernanceprinciples/31557724.pdf/. 
—. 2014. "Education at a Glance 2014: OECD Indicators." http://dx.doi. org/10.1787/eag-2014-en/.

Paredes, Ricardo. 2012. “Universidad y lucro, o el dilema de la cobertura.” Estudios Públicos 128: 174-185.

Peña, Carlos. 2012. "La universidad y el lucro: cómo impedirlo y por qué." Estudios Públicos 128: 116-136.

Rama, Claudio. 2011. "La educación superior privada en Brasil." Revista Histedbr On-Line 11 (44): 3-17. https://www.fe.unicamp.br/revistas/ged/histedbr/ article/view/3118/2773/.

The Carnegie Classification of Institutions of Higher Education. http:// carnegieclassifications.iu.edu/summary/basic.php/.

The Economist. 2015. "Special Report: Universities." 28 de marzo.

Valenzuela, Ignacio. 2015. "La prohibición a los fines de lucro y propuestas de gobierno para las universidades chilenas." Serie Propuestas de Política Pública 9, Centro de Estudios Públicos. http://www.cepchile.cl/1_5930/doc/ la_prohibicion_a_los_fines_de_lucro_y_propuestas_de_gobierno_para_las_ universid.html\#.VWiaTc9Vikp/.

Vargas, Ernesto \& Claudia Martínez. 2012. "Evaluación del sistema de franquicias tributarias para donaciones a universidades en Chile." Trabajos de Investigación en Políticas Públicas 12. http://www.econ.uchile.cl/uploads/ publicacion/aa496d822815db1c812d016694dc5ee46c98e685.pdf/.

Williamson, Carlos. 2012. "Universidad y lucro”. Estudios Públicos 128: 137-156.

\section{Normas, dictámenes y otros documentos oficiales chilenos:}

Código Civil. República de Chile.

Contraloría General de la República de Chile. "Financiamiento fiscal a la educación superior 2014." http://www.contraloria.cl/NewPortal2/portal2/ShowProperty/ BEA\%20Repository/Portal/Bases/Contabilidad/Universidades_del_Estado/ Estudios/2014/FFES.pdf/.

Decreto con Fuerza de Ley N. ${ }^{\circ} 1$ del Ministerio de Educación Pública del 3 de enero de 1981. "Fija normas sobre universidades." República de Chile.

Decreto con Fuerza de Ley N. 2 del Ministerio de Educación del 2 de julio de 2010. "Fija texto refundido, coordinado y sistematizado de la Ley N. ${ }^{\circ} 20.370$ con las normas no derogadas del Decreto con Fuerza de Ley N. ${ }^{\circ}$ 1, de 2005." República de Chile.

Instituto Nacional de Estadísticas de Chile. "Chile proyecciones y estimaciones de población. Total país 1950-2050.” http://www.ine.cl/canales/chile_estadistico/ demografia_y_vitales/proyecciones/Informes/MicrosoftWordInforP_T.pdf/.

Ley N. ${ }^{\circ} 18.046$ del 22 de octubre de 1981. "Ley sobre sociedades anónimas." República de Chile.

Ley N. ${ }^{\circ} 18.956$ del 8 de marzo de 1990. "Reestructura el Ministerio de Educación Pública." República de Chile. 
Ley N. ${ }^{\circ} 18.962$ del 10 de marzo de 1990. "Ley orgánica constitucional de enseñanza." República de Chile.

Ministerio de Educación de Chile. "Becas y créditos 2015." http://www.mineduc. cl/usuarios/becasycreditos/doc/201411181621000.insertoBYC_2015VF.pdf/.

Presidencia de la República de Chile. "Mensaje de S.E. el Presidente de la República con el que inicia un proyecto de ley que crea la Superintendencia de Educación Superior (Mensaje N. ${ }^{\circ}$ 277-359).” 10 de noviembre de 2011.

Servicio de Información de Educación Superior de Chile. "Deserción \& reingreso a educación superior en Chile, análisis de la cohorte 2008." http:// www.mifuturo.cl/images/Estudios/Estudios_SIES_DIVESUP/desercion_ reingreso_a_educacin_superior.pdf/.

Servicio de Información de Educación Superior de Chile. "Evolución de la matrícula de pregrado por tipo de institución 1983-2013." http://www. mifuturo.cl/index.php/estudios/estructura-compendio/.

Servicio de Información de Educación Superior de Chile. "Informe matrícula 2014." http://www.mifuturo.cl/index.php/informes-sies/matriculados/.

Servicio de Información de Educación Superior de Chile. "Panorama de la educación superior en Chile 2014." http:/www.mifuturo.cl/images/Estudios/ Estudios_SIES_DIVESUP/panorama_de_la_educacion_superior_2014_sies. pdf/.

Superintendencia de Valores y Seguros de Chile. Norma de Carácter General N. ${ }^{\circ}$ 341. 29 de noviembre de 2012.

Superintendencia de Valores y Seguros de Chile. Norma de Carácter General N. ${ }^{\circ}$ 385. 8 de junio de 2015 .

\section{Normas y jurisprudencia extranjera:}

Delaware General Corporation Law. Estado de Delaware. Estados Unidos.

New York Not-for-Profit Corporation Law. Estado de Nueva York. Estados Unidos.

Weinberger v. UOP, INC., 457 A.2d 701 (Del. 1983). EP 